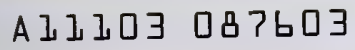

ENT OE

NATL INST OF STANDARDS \& TECH R.I.C.

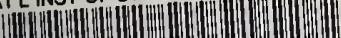

m.

A1 1103087603

Novotny, Donald B/Automated photomask in
N

actoo.

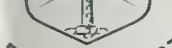

¿upeau of $s^{\text {Ap }}$

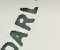

INBS SPECIAL PUBLICATION

$400-46$

U.S. DEPARTMENT OF COMMERCE / National Bureau of Standards

Semiconductor Measurement Technology:

\author{
Automated \\ Photomask Inspection
}


Semiconductor Measurement Technology:

\section{Automated Photomask Inspection}

\section{Donald B. Novotny}

Electronic Technology Division Institute for Applied Technology National Bureau of Standards

Washington, D.C. 20234

and

Dino R. Ciarlo

Lawrence Livermore Laboratory

P. O. Box 808

Livermore, CA 94550

This activity was supported by

The Defense Advanced Research Projects Agency

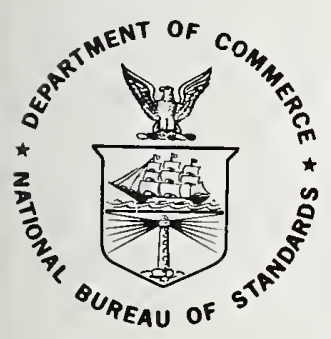

U.S. DEPARTMENT OF COMMERCE, Juanita M. Kreps, Secretary

Dr. Sidney Harman, Under Secretary

Jordan J. Baruch, Assistant Secretary for Science and Technology

NATIONAL BUREAU OF STANDARDS, Ernest Ambler, Director

Issued April 1978 


\section{Library of Congress Catalog Card Number: 78-606023}

National Bureau of Standards Special Publication 400-46

Nat. Bur. Stand. (U.S.), Spec. Publ. 400-46, 38 pages (Apr. 1978) CODEN: XNBSAV 
Abstract . . . . . . . . . . . . . . . . . . . . . . . . . . 1

1. Introduction . . . . . . . . . . . . . . . . . . . . . . . . . 2

2. Inspection for Visual Defects . . . . . . . . . . . . . . . . . . 4

2.1 Optical-Overlay Method . . . . . . . . . . . . . . . . . . . 4

2.2 TV-Microscope Method . . . . . . . . . . . . . . . . . . . . 8

2.3 Spatial-Filtering Method . . . . . . . . . . . . . . . . . . . 12

2.4 Dua1-Beam, Flying-Spot-Scanner Method . . . . . . . . . . . . . . . 13

3. Inspection for Dimensional Defects . . . . . . . . . . . . . . . . . . 14

3.1 Line-Edge Location . . . . . . . . . . . . . . . . . . . . . 14

3.2 Criteria for Microdensitometer Operation . . . . . . . . . . . . . . 15

3.3 Applications to Mask Inspection . . . . . . . . . . . . . . . . . . . 19

4. Experimental Evaluation of Automated Inspection Systems . . . . . . . . 21

4.1 Test Masks . . . . . . . . . . . . . . . . . . . . . . . . . 21

4.2 Mask Inspection . . . . . . . . . . . . . . . . . . . . . . . 21

5. Conclusions . . . . . . . . . . . . . . . . . . . . . . . 27

6. Acknowledgments . . . . . . . . . . . . . . . . . . . . . . 27

7. References . . . . . . . . . . . . . . . . . . . . . . . 28

Appendix . . . . . . . . . . . . . . . . . . . . . . . . . . . . . 30 
Figure 1. A schematic drawing illustrating the optical-overlay method . . . . 5

Figure 2. Convolution of two identical apertures in one dimension . . . . . 5

Figure 3. Illustration of the worst overlap case between the "diode" apertures and the "pinhole" aperture . . . . . . . . . . 7

Figure 4. Block diagram of TV-microscope automatic mask inspection system ...................... . 9

Figure 5. Line-edge profiles for coherent radiation showing $A$, the physical profile; $B$, the transmittance of edge A; C, D, and $E$ are transmittance profiles of edge A obtained by scanning with coherent Gaussian light spots of $1-, 2-$, and $3-\mu \mathrm{m}$ diameters, respectively. The invariant point is located by $\mathrm{T}_{\mathrm{C}}=$ 0.325 for the case where $\mathrm{T}_{0}=0.02$. . . . . . . . . . 14

Figure 6. Schematic of a microdensitometer-digital computer mask inspection system . . . . . . . . . . . . . . 16

Figure 7. The 14 by 14 matrix of the defect mask showing the stepped locations of the three different defect reticles indicated by Roman numerals I, II, and III, respectively . . . . . . . . 22

Figure 8. The run-out errors between the left edges on adjacent dice of row 12 of the defect mask as a function of column position . . . 23

Figure 9. Illustration of the run-out errors from the scan measurements of the line centers . . . . . . . . . . . . . . . . 24 
Table 1. Characteristics of Automated Photomask Inspection Methods

for Visual Defects . . . . . . . . . . . . . . . . . . . 3

Table 2. Values of Inspection Parameters for the Optical-Overlay

Method on a 76- by 76-mm Mask . . . . . . . . . . . . . . . . . 9

Table 3. Critical Parameters for TV-Microscope Mask Inspection Systems with a $20-$ by $20-m m$ Image Tube Target . . . . . . . . . . . . . . 9

Table 4. Scan Times for Two State-of-the-Art TV-Microscope Mask

Inspection Systems . . . . . . . . . . . . . . . . . . . 11

Table 5. Comparison of Total Edge Offset for a Line-Width Measurement When the Edges are Located at the Invariant Point and the 0.5 Transmittance Point, Respectively . . . . . . . . . . . . 15

Table 6. Calculated Values of Lens Parameters Dependent on Numerical Aperture, for Diffraction-Limited Optics at a Wavelength of $500 \mathrm{~nm}$. . . . . . . . . . . . . . . . . 16

Table 7. Calculated Maximum Spatial Frequencies for Linear Response at $500 \mathrm{~nm}$. . . . . . . . . . . . . . . . . . 18

Table 8. Intentional Defects on the Defective Die . . . . . . . . . . . . 22 
This study was carried out at the Lawrence Livermore Laboratory and the National Bureau of Standards as part of the Semiconductor Technology Program in the Electronic Technology Division at the National Bureau of Standards. The Semiconductor Technology Program serves to focus NBS research to enhance the performance, interchangeability, and reliability of discrete semiconductor devices and integrated circuits through improvements in measurement technology for use in specifying materials and devices in national and international commerce and for use by industry in controlling device fabrication processes. The work was supported by the Defense Advanced Research Projects Agency (ARPA Order 2397, Program Code 6D10). The work at Lawrence Livermore Laboratory was conducted under NBS Order Numbers 503183 and 602156. 


\author{
Donald B. Novotny \\ Institute for Applied Technology \\ National Bureau of Standards \\ Washington, D. C. 20234 \\ and \\ Dino R. Ciarlo \\ Lawrence Livermore Laboratory \\ Livermore, CA 94550
}

\begin{abstract}
Methods that may be suitable for automated photomask inspection for visual defects (spots, pinholes, etc.) or dimensional compliance are analyzed and discussed. The analysis of each method includes examinations of the physical principles upon which it is based and the amount of misalignment that can be tolerated. The size of the minimum visual defect to be detected was taken as $2 \mu \mathrm{m}$. The methods analyzed for visual defect inspection are the optical-overlay; the dual-beam, flyingspot-scanner; the TV-microscope; and the spatial-filtering methods. For dimensional inspection, an analysis of line-edge location and operating criteria for the microdensitometer are presented. The fabrication of photomasks with intentionally introduced and controlled defects is described together with preliminary results of automated inspections of these photomasks. It was concluded that: automated inspection systems should be dedicated either to inspection for visual defects or dimensional compliance, not both; and the dimensional tolerances on masks, both those of the feature dimensions in the die patterns as well as those in the dimensions between the dice, must be significantly smaller than the size of the minimum defect to be detected.
\end{abstract}

Key Words: Alignment tolerance; automated photomask inspection; dimensional inspection; flying-spot scanner; microdensitometer; optical overlay; photomask; spatial filtering; TV-microscope; visual defect inspection. 
Both visual and dimensional defects may occur in photomasks. Visual defects are so named because they are detected by visual observations with no dimensional measurements; they consist of pinholes, spots, intrusions, protrusions, etc. in the die pattern geometry. Dimensional defects are so named because they are dimensional errors in the die pattern geometry.

Both types of defects cause yield losses in the production of integrated circuits. Visual observations and measurements through a microscope are generally used to detect these defects and thereby identify defective photomasks so they are not used in the fabrication of integrated circuits. These nonautomated inspection methods are fatiguing, of questionable accuracy, and provide neither 100percent inspection of the mask nor a 100percent probability of the detection of any visual defect [1]. Automated inspection of photomasks can in principle provide 100percent inspection and perform this inspection with a greater probability of defect detection in a much shorter time than nonautomated methods and thereby benefit the electronics industry.

A study of the electronics industry throughout the country [2] was conducted to determine the requirements for automated photomask inspection systems, and to identify methods or technologies that appear feasible for automated inspection. From this study it was concluded that: for visual defect inspection, a viable automated inspection system should be able to detect defects that are $2 \mu \mathrm{m}$ or larger in dimensions, and for dimensional inspection, pattern registration and critical dimensions should be measured with uncertainties of a few tenths of a micrometer or less. A further requirement was that 100-percent mask inspection for either visual or dimensional defects on a 3- by 3-in. (76- by 76-mm) photomask should take a maximum time of about 15 min.

Four methods appeared suitable for automated photomask inspection for visual defects: the direct comparison of the image of one die pattern with another on the same mask, which is called the optical-overlay method; (2) the comparison of a microscope die pattern image which is digitized through the use of a TV tube with information representing the defectfree pattern stored in a computer memory, which is called the TV-microscope method; (3) the identification of visual defects by the optical spatial filtering of the image of the die pattern in a manner that the defects are easily seen, which is called the spatialfiltering method; and (4) the direct comparison of die patterns by simultaneously scanning, with two small spots of light, two corresponding positions on different die patterns, which is called the dual-beam, flyingspot-scanner method.

Microdensitometry was the only method that appeared readily adaptable to automated dimensional inspection. Thus, criteria for the use of the microdensitometer for accurate dimensional inspection are presented with a discussion of line-edge location. These criteria are also applicable to the opticaloverlay, TV-microscope, and dual-beam, flying-spot-scanner methods if these methods are used for dimensional inspection.

All of the analyses were performed with respect to an arbitrarily defined "standard" photomask which is representative of the masks now used in the electronics industry: a 76 - by $76-\mathrm{mm}$ mask with 3.8 - by $3.8-\mathrm{mm}$ die patterns forming a 20 by 20 matrix. The size of the smallest defect to be detected was taken as $2 \mu \mathrm{m}$. The calculated inspection times for the respective methods do not include the loading and system adjustment times. Table 1 summarizes the characteristics of these methods; the estimated equipment costs listed in this table are primarily based on estimates given by persons working with similar equipment and are intended only to provide comparisons between the various methods.

In the last part of this investigation, test photomasks with intentionally introduced defects were made. These were intended for use in determining, for a particular inspection system, the minimum detectable defect sizes, inspection speeds, missing defects, probabilities of defect detection, and the numbers of false defects detected. These masks could also serve as a means whereby anyone could evaluate his own automated inspection system for his particular application.

Such test masks could also be used on a regular basis to verify the performance of operating systems [3]. The results of inspections of these masks with some existing inspection systems indicated that automated inspection methods are limited by the precision of the die step-and-repeat distance. 
Table 1 - Characteristics of Automated Photomask Inspection Methods for Visual Defects

\begin{tabular}{lcccc} 
Method & $\begin{array}{c}\text { Inspection } \\
\text { Sampling } \\
\text { Rate, s }\end{array}$ & $\begin{array}{c}\text { Total } \\
\text { Inspection } \\
\text { Time, h:min }\end{array}$ & $\begin{array}{c}\text { Required } \\
\text { Alignment } \\
\text { or Indexing } \\
\text { Accuracy, } \mu \mathrm{m}\end{array}$ & $\begin{array}{c}\text { Estimated } \\
\text { Equipment } \\
\text { Cost, } \mathrm{k} \$\end{array}$ \\
\hline $\begin{array}{l}\text { Optical Overlay } \\
\text { TV-Microscope }\end{array}$ & $3.0 \times 10^{6}$ & $0: 5$ & $< \pm 1$ & 150 \\
$\begin{array}{l}\text { Spatial Filtering } \\
\text { Dual-Beam, Flying-Spot } \\
\quad \text { Scanner }\end{array}$ & $3.5 \times 10^{6}$ & $0: 50$ & $< \pm 0.4$ & 130 \\
\begin{tabular}{l} 
Microdensitometer \\
\hline
\end{tabular} & $1.5 \times 10^{4}$ & $\sim 26: 4$ & $\mathrm{NA}$ & 100 \\
\hline
\end{tabular}




\subsection{Optical-Overlay Method}

Principles of Operation - In this method two die patterns are viewed simultaneously through two respective microscope objectives as shown in figure 1. The fields of view of the two objectives are illuminated continuously by transmitted light and the resultant images are projected onto the respective linear photodiode array. The sample is scanned in the $\mathrm{x}$-direction by means of a mechanical stage and the widths of the inspected swaths are determined by the long dimensions of the respective linear photodiode arrays which are each oriented in the $\mathrm{y}$-direction, perpendicular to the stage scanning direction. The swaths are raster scanned simultaneously by serially interrogating each diode of each of the arrays. In this manner pattern information from corresponding coordinate positions on two die patterns is simultaneously read by the two diode arrays. This information consists of each individual diode exposure which is the total light energy incident on each diode during the time between its successive interrogations.

The photodiodes of each array are interrogated by electronic circuitry. The capacitance for each diode is charged to the video line potential and left open-circuited until the next interrogation. During this opencircuited period, the diode capacitance will be discharged by an amount proportional to the diode exposure providing saturation exposure is not reached. Each time a diode is sampled, its capacitance is recharged through the video line. The resulting video signal for each array is a train of charge pulses, each having a magnitude proportional to the exposure on a particular photodiode. This signal from each device in one of the arrays is subtracted from the signal of the corresponding diode on the other array. A nonzero difference signal is interpreted as a defect since it arises from differences in transmission between corresponding locations on two die patterns.

Analysis - The analysis of this method requires the calculation of the exposure received by a diode when two apertures cross over each other as the stage scans. These apertures are effectively formed on the sample plane by a pinhole defect in the mask and the projection of a diode through the objective. To calculate the scanning rate, typical photodiode array specifications are combined with the exposure calculation. This, in turn, is used to calculate the inspection time, the required light intensity at the sample plane, and the tolerance for the die-todie spacing. Implicit in this analysis is that the microscope objectives have sufficient resolution to image the smallest defect to be detected. This required resolution is determined by the smallest dimension, $\delta$, of the defect to be detected, and is related to the minimum numerical aperture, $\mathrm{NA}_{\min }$, of the objective by

$\mathrm{NA}_{\text {min }}=1.2 \lambda / \delta$

where $\lambda$ is the wavelength of the light. This equation is based on the criterion that the light intensity be zero between the nearest two points to be resolved [4].

The first step in the calculation of the diode exposure is to calculate the area in common, or the overlap, between the pinhole and diode apertures as they pass over each other. In one dimension the overlap between two apertures, each q $\mu \mathrm{m}$ wide, as they pass over each other, or the one-dimensional autoconvolution, $C(\zeta)$ is

$$
C(\zeta)= \begin{cases}\zeta & 0<\zeta \leq q \\ 2 q-\zeta & q<\zeta<2 q, \text { and } \\ 0 \text { for all } & \text { other values of } \zeta,\end{cases}
$$

where $\zeta$ is the distance between the leading edge of one aperture of dimension $q$ and the trailing edge of the other aperture as shown in figure 2. The autoconvolution function is proportional to the instantaneous amount of light incident on a diode. From eq (2) and figure 2 it may be seen that $C(\zeta)$ is nonzero over a distance of $2 \mathrm{q}$ or twice the aperture dimension. This function may be applied in both the $\mathrm{x}-$ and $\mathrm{y}$-directions to obtain the two-dimensional convolution of the apertures. When the two-dimensional convolution is multiplied by the illuminating intensity at the sample plane $\left[\left[\mathrm{W} / \mathrm{cm}^{2}\right]\right.$, the product is the rate of energy per square centimeter falling on the diode, $E(x, y)$, as a function of the relative positions of the two apertures, or

$E(x, y)=\operatorname{IC}(x) C(y)$.

The specifications of the typical linear photodiode array in this analysis are:

$$
\begin{aligned}
\mathrm{N}= & 512=\text { number of in-line photodiodes, } \\
\mathrm{f}= & 2 \times 10^{6} \mathrm{~Hz}=\text { photodiode scanning fre- } \\
& \text { quency, }
\end{aligned}
$$




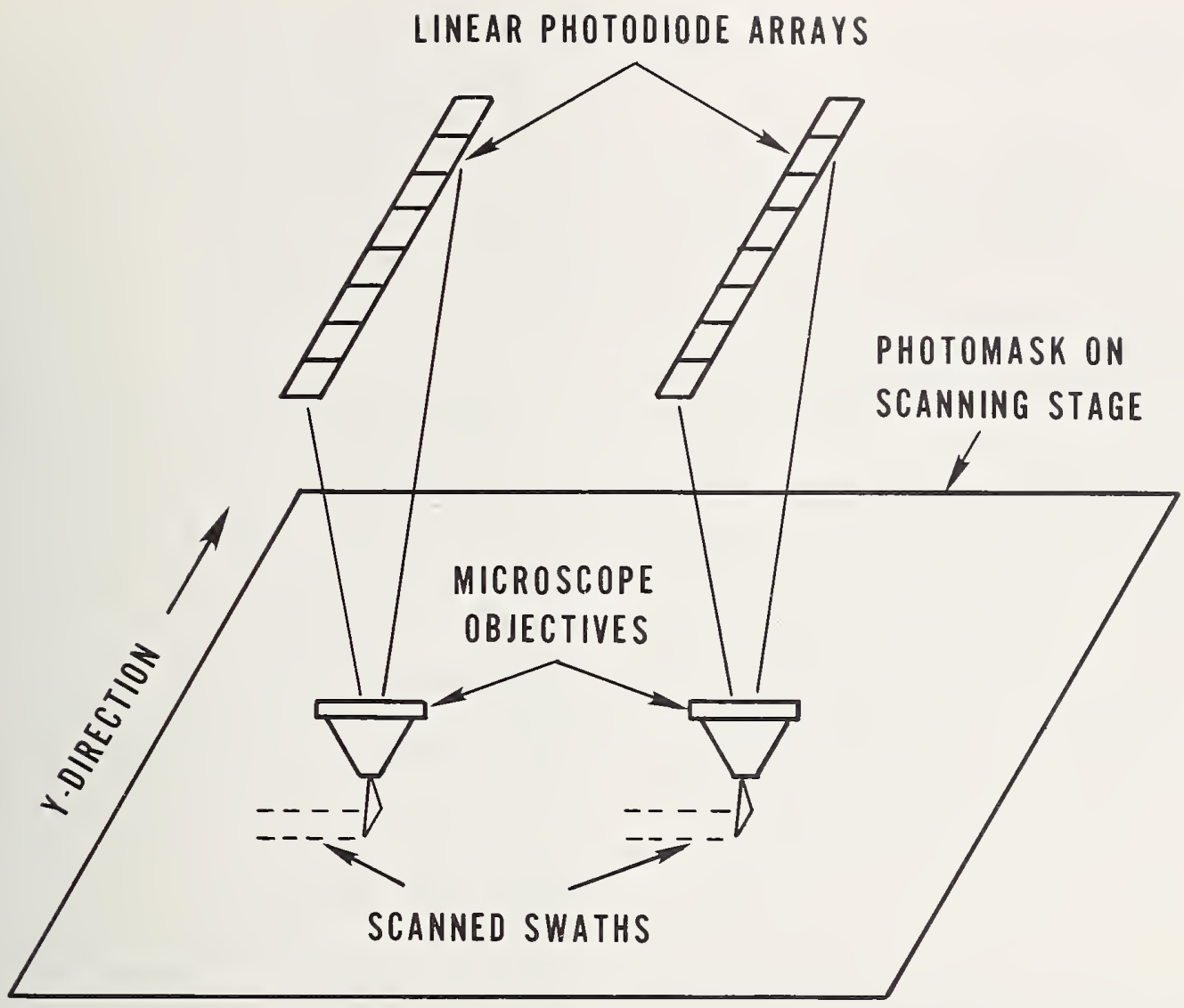

\section{$X$-DIRECTION}

Figure 1. A schematic drawing illustrating the optical-overlay method. (The small segments in the photodiode arrays illustrate the individual photodiodes which make up the arrays. Illumination is transmitted through the mask into the objectives which focus the patterns on the arrays.)

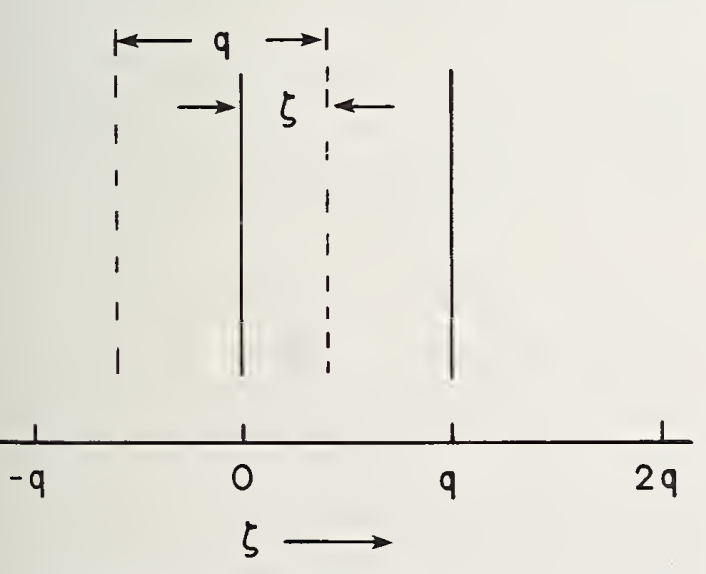

a. Illustration of the physical convolution; one aperture, represented by the solid lines, remains stationary. while the other aperture, represented by the dashed lines, moves across it.

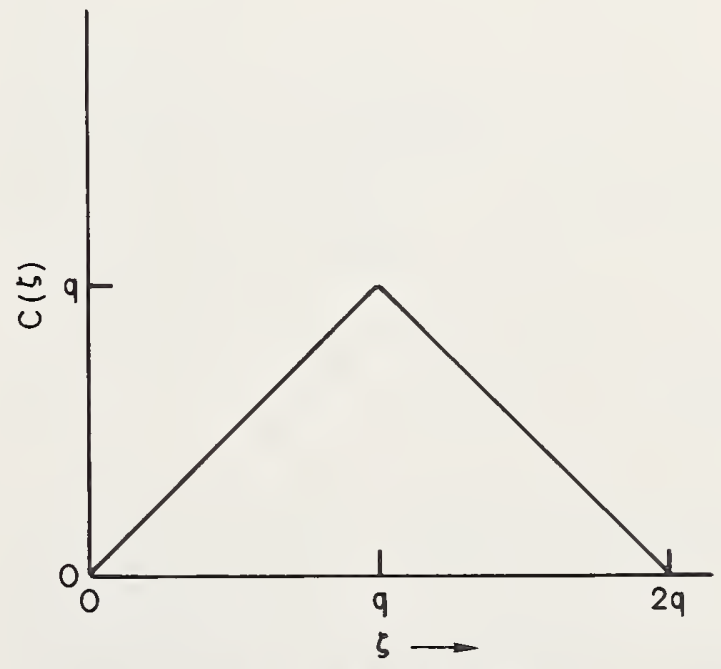

b. The value of the one-dimensional overlap or convolution $\mathrm{C}(\zeta)$ as a function of $\zeta$.

Figure 2. Convolution of two identical apertures in one dimension. 
$\mathrm{D}_{\mathrm{d}}=25 \mu \mathrm{m}=$ edge dimension of each photodiode,

$\mathrm{L}=13 \mathrm{~mm}=1$ ength of the array, and

$E_{\mathrm{S}}=5.7 \mu \mathrm{W} \cdot \mathrm{s} / \mathrm{cm}^{2}=$ saturation exposure, or the exposure necessary to completely discharge the diode capacitance.

The optimum stage scanning velocity may now be calculated by applying the results of the aperture convolution, the dimensions of a single diode of the array, and the dimensions of a pinhole of minimum detectable size. To use the photodiode most effectively, the image of the pinhole must exactly fill the diode. This choice of conditions is based on the following: if the minimum defect aperture "underfills" the diode aperture, a more intense source is required for detection as will be shown later in this analysis; if the minimum detectable defect aperture "overfills" the diode, more than one diode is required for the detection of a minimum size defect and the utilization efficiency of the diode is reduced. These conditions require that the magnification of the objective lens be $M=D_{d} / q$, which is equal to 12.5 for this analysis.

The scanning velocity of the stage is determined from the requirement that the stage advance a distance $2 \mathrm{q}$, the nonzero range of the autoconvolution function, during the time between two successive interrogations of the same photodiode, namely, $\mathrm{t}_{\mathrm{a}}=\mathrm{N} / \mathrm{f}$. This gives a stage scan velocity $v_{x}$ of

$v_{x}=\frac{2 q}{N / f}=2.34 \mathrm{~cm} / \mathrm{s}$

where the subscript $x$ denotes the scan direction. Since the width of each swath is given by $\mathrm{L} / \mathrm{M}$, which is approximately $1 \mathrm{~mm}, 76$ nonoverlapping scans are required to completely inspect the mask. Since each scan is $76 \mathrm{~mm}$ long, a total mask inspection time of $4 \mathrm{~min}$, $7 \mathrm{~s}$ is needed, plus the time required for stage reversing and indexing. It is estimated that these additional functions can be completed in less than 1 min to give a total inspection time of about $5 \mathrm{~min}$.

It must still be shown that it is possible to attain sufficient light intensity to detect the minimum size defect. The required intensity at the sample plane is calculated from the light energy required for a minimum exposure of a photodiode. A diode is exposed by light energy passing through the "aperture shutter" formed by the crossing of the two apertures as the stage scans. This energy is incident on the diode for the duration that this "shutter" remains open and constitutes the diode exposure. This diode exposure must be equal to or greater than the minimum energy, $\Delta \mathrm{U}_{\mathrm{d}}$, which is detectable on the photodiode and is typically 1 percent of the diode saturation exposure multiplied by the diode area $A_{d}$ or

$$
\Delta \mathrm{U}_{\mathrm{d}}=(0.01) \mathrm{E}_{\mathrm{s}} \mathrm{A}_{\mathrm{d}}=3.56 \times 10^{-7} \mu \mathrm{W} \cdot \mathrm{s} .
$$

The diode exposure must exceed $\Delta \mathrm{U}_{\mathrm{d}}$ when the worst possible alignment between the two apertures is realized to ensure the detection of the minimum size defect. The worst alignment occurs, as shown in figure 3 , when the pinhole aperture overlaps half of a diode aperture in the $y$-direction and the apertures are in complete coincidence in the $\mathrm{x}$-direction at the time of diode interrogation. Under these conditions only half a convolution is completed between interrogations and the diode exposure lasts for a time of only N/2f. From figure 3 it may be seen that any change in the alignment in the $y$-direction for one diode will only serve to increase the overlap between the pinhole and an adjacent in-line diode of the array, and that any change in the $\mathrm{x}$-direction alignment will cause more than half of the convolution to be completed during the time between successive interrogations and increase the exposure of the diode. The best alignment occurs when the $y-$ dimension of the pinhole and the diode aperture are in perfect coincidence and, in the $\mathrm{x}$-direction, the leading edge of one of the apertures is just touching the opposite edge of the other. Under these conditions, the apertures will completely convolve between interrogation times.

The diode exposure for the worst case is mathematically written as the integral of $\mathrm{E}(\mathrm{x}, \mathrm{y})$ of eq (3), with $\mathrm{x}=\mathrm{v}_{\mathrm{x}} \mathrm{t}$ and $\mathrm{C}(\mathrm{y})=$ $\mathrm{C}(\mathrm{q} / 2)$, and expressed as

$\Delta \mathrm{U}_{\mathrm{d}} \leq(\mathrm{qI} / 2) \int_{0}^{\mathrm{i} / 2 \mathrm{f}} \mathrm{v}_{\mathrm{x}} \mathrm{tdt}=\mathrm{E}_{\mathrm{m}} \mathrm{I}$

where

$$
E_{m}=q^{2} N / 8 f
$$

This expression may be evaluated to obtain the minimum intensity required for a detectable signal.

The upper limit of the illumination intensity in the sample plane which will cause diode saturation is realized when a completely 


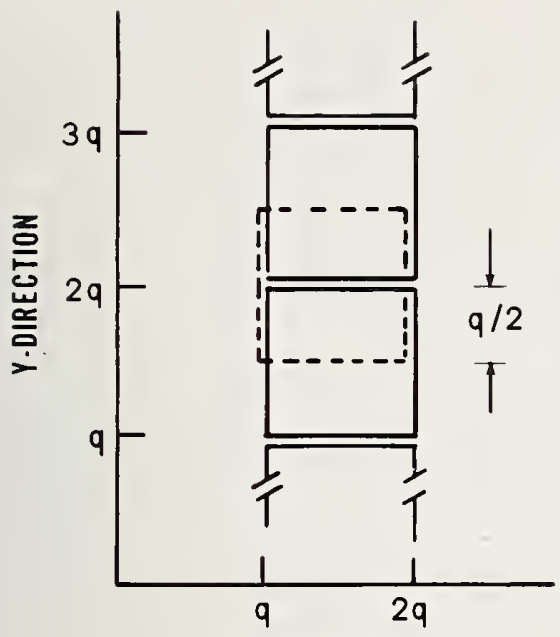

$X$-DIRECTION

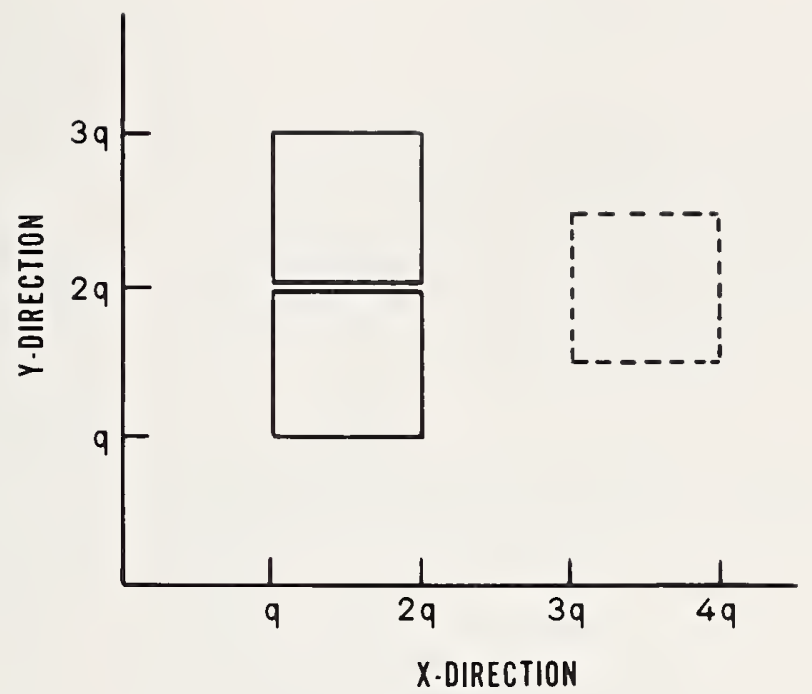

b. Relative positions of the apertures shown in (a) at the time of the second interrogation. a. Position of the "pinhole" aperture with respect to the apertures formed by the inline photodiodes at the position of the first interrogation.

Figure 3. Illustration of the worst overlap case between the "diode" apertures (solid lines) and the "pinhole" aperture (dashed lines).

clear field instead of a pinhole is viewed during the time between successive interrogations of a diode. This exposure is equal to the area of the aperture in the sample plane formed by the projection of a single diode through the objective, namely $q^{2}$, multiplied by the diode interrogation time $N / f$ or, $q^{2} N / f$ $=8 \mathrm{E}_{\mathrm{m}}$. To avoid diode saturation the maximum intensity $8 \mathrm{E}_{\mathrm{m}} \mathrm{I}$ must be less than $100 \Delta \mathrm{U}_{\mathrm{d}}$. This gives the following intensity range

$$
\frac{100 \Delta \mathrm{U}_{\mathrm{d}}}{8 \mathrm{E}_{\mathrm{m}}}>\mathrm{I}>\frac{\Delta \mathrm{U}_{\mathrm{d}}}{\mathrm{E}_{\mathrm{m}}} .
$$

When this expression is evaluated, the following intensity range is obtained:

$$
5250 \mathrm{~mW} / \mathrm{cm}^{2}>\mathrm{I}>420 \mathrm{~mW} / \mathrm{cm}^{2} \text {. }
$$

The minimum intensity is quite high in comparison to the intensity received at the earth's surface on a clear, bright day, which is of the order of $100 \mathrm{~mW} / \mathrm{cm}^{2}$. However, intensities up to $1 \mathrm{~W} / \mathrm{cm}^{2}$ should be attainable at the sample plane by focusing high intensity sources or a laser beam down to a spot size slightly larger than the field of view formed by the projection of the diode array onto the sample plane.

The calculated minimum required intensity is equally valid for the detection of an opaque spot of $q$ by $q$ dimensions in a transparent field. The net signal difference between two charge pulses, each from a corresponding díode on each diode array, varies from zero when both diodes receive exactly the same exposure, to a maximum that occurs when one diode views a clear field and receives a maximum exposure of $8 \mathrm{E}_{\mathrm{m}} \mathrm{I}$ while the other receives zero exposure. The net signal obtained when a transparent pinhole of minimum detectable size is "viewed" by one diode while the corresponding diode "views" an opaque field corresponds to a net exposure of $\mathrm{E}_{\mathrm{m}} \mathrm{I}$. The analogous case for the opposite polarity occurs when one diode is exposed to an opaque spot of minimum detectable size while the other is exposed to a clear field; for this case the net differential signal is again $E_{m} I$, which is equal to the exposure, $7 \mathrm{E}_{\mathrm{m}} \mathrm{I}$, on the diode "viewing" the defect, subtracted from the signal of the diode "viewing" the clear field.

The model used for obtaining the minimum exposure can be extended to determine the tolerance of the die-to-die spacing between the edges of corresponding geometries on different die patterns to avoid spurious defect detection. Values for this alignment tolerance are obtained by realizing that the total misalignment must produce exposures less than those produced by minimum detectable defects. Such exposures will be obtained if the misalignments $\Delta x$ and $\Delta y$ of two edges in each of these directions are no greater than $q / 2$, or 
$\Delta \mathrm{x}=\Delta \mathrm{y}< \pm \mathrm{q} / 2= \pm 1 \mu \mathrm{m}$.

Misalignment can also result from a lack of consistency in line widths on different die patterns and yaws in the stage motion of the inspecting stage. These tolerances represent the maximum tolerable misalignment; it is estimated that the actual misalignment tolerance should probably be less than 70 percent of these values to prevent copious spurious defect detections.

From the above analysis it may be seen that the inspection time, scan velocity, lens magnification, and acceptable intensity range are functions of the dimensions of the minimum detectable defect and the interrogation frequency of the photodiode. Table 2 summarizes these parameters for 2- by $2-\mu \mathrm{m}$ and 4by $4-\mu \mathrm{m}$ defects and interrogation frequencies of $3 \mathrm{MHz}$ and $1 \mathrm{MHz}$. The scanning times in this table do not include either indexing time or time for loading the mask into the system and its subsequent alignment.

Although this inspection time is much less than required, the method has a serious shortcoming, namely, it is insensitive to any defect which is repeated on all die patterns since defects are detected by differences between die patterns.

Application - Recently, an automatic mask inspection system has been reported [5] which, despite the absence of a description of the detection method, appears to use the opticaloverlay method to detect defects. In this system compensation for misalignment is made electronically through the use of computer interrogated data. This system is also capable of being programmed to inspect only predesignated areas of the die patterns on the mask which reduces its inspection time and increases the probability that a detected defect will be fatal. The quoted inspection rate is $2 \mathrm{in}^{2} / \mathrm{min}\left(12.9 \mathrm{~cm}^{2} / \mathrm{min}\right)$ which implies that inspection of a 76- by 76-mm mask can be done in about $4.5 \mathrm{~min}$, which is in good agreement with the calculated times.

\subsection{TV-Microscope Method}

Principles of Operation - This method also utilizes a microscope and digitization of the image of the field of view. It consists of a system which employs a TV camera tube to view the array of patterns through a single microscope. The photomask is on a movable stage which is stepped across the field of view of the microscope. The photomask pattern information is imaged on the tube target, digitized, and compared with data that represent the correct pattern and is stored in a computer memory. This technology has its primary application in visual defect detection. It may also be applied to registration inspection provided that the position of the stage is known to sufficient accuracy. For this application it is necessary to use either a linear encoder or a laser interferometrically controlled stage. A schematic diagram of the system is shown in figure 4 .

Analysis - The required resolution of the microscope objective for this method is the same as that for the optical-overlay method and is determined by the smallest dimension, $\delta$, of the defect that is to be detected.

This resolution determines the minimum value of the numerical aperture, $\mathrm{NA}_{\min }$, of the objective in accordance with eq (1):

$\mathrm{NA}_{\min }=1.2 \lambda / \delta$.

For $\delta=2 \mu \mathrm{m}$ and $\lambda=0.55 \mu \mathrm{m}$, a numerical aperture of 0.33 or larger is required.

A microscope objective with the desired magnification, $\mathrm{M}_{\mathrm{obj}}$, may be selected from a host of commercially available objectives provided the numerical aperture criterion is satisfied. However, one must also consider the field of view of the objective because it is this that determines in part how fast the mask may be inspected. An objective with a higher magnification produces a larger image at the expense of reducing the size of the field of view. To utilize the tube target efficiently, the projected image must fill the target area which is usually square or rectangular. Consequent1y, the smaller of the target dimensions, $\varepsilon$, the side, $s$, of the square inscribed in the circular field of view of the microscope objective, and the total optical magnification of the microscope, $\mathrm{M}_{\text {tot }}$, are related by

$\mathrm{M}_{\text {tot }}=\varepsilon / \mathrm{s}$.

The smallest image dimension that must be resolved by the tube, $R_{r}$, is the product of the smallest defect dimension, $\delta$, times the total optical magnification:

$R_{r}=\delta M_{\text {tot }}$.

The minimum number of scanned lines per millimeter, $\ell$, is the reciprocal of this product. Calculated values for comparison of these parameters are given in table 3 for a $20-$ by $20-\mathrm{mm}$ target and selected values of $\delta$ and $\mathrm{M}_{\mathrm{obj}}$. For these calculations $\lambda$ was chosen as $0.55 \mu \mathrm{m}$, and the values of $\mathrm{s}$ were calculated assuming fields of view of typical microscope objectives [4]. 
Table 2 - Values of Inspection Parameters for the Optical-Overlay Method on a 76- by 76-mm Mask. (Specifications of the diode array are given in the text.)

\begin{tabular}{cccccc}
\hline $\begin{array}{c}\text { Defect } \\
\text { size, } \mu \mathrm{m}\end{array}$ & $\mathrm{f}, \mathrm{MHz}$ & $\mathrm{M}$ & $\mathrm{v}_{\mathrm{x}}, \mathrm{cm} / \mathrm{s}$ & $\begin{array}{c}\text { Scanning } \\
\text { time, min:sec }\end{array}$ & $\begin{array}{c}\text { Minimum } \\
\mathrm{I}, \mathrm{mW} / \mathrm{cm}^{2}\end{array}$ \\
\hline $2 \times 2$ & 3 & 12.5 & 2.34 & $4: 07$ & 420 \\
$4 \times 4$ & 3 & 6.25 & 4.68 & $1: 02$ & 105 \\
$2 \times 2$ & 1 & 12.5 & 0.78 & $12: 21$ & 140 \\
$4 \times 4$ & 1 & 6.25 & 1.56 & $3: 05$ & 35 \\
\hline
\end{tabular}

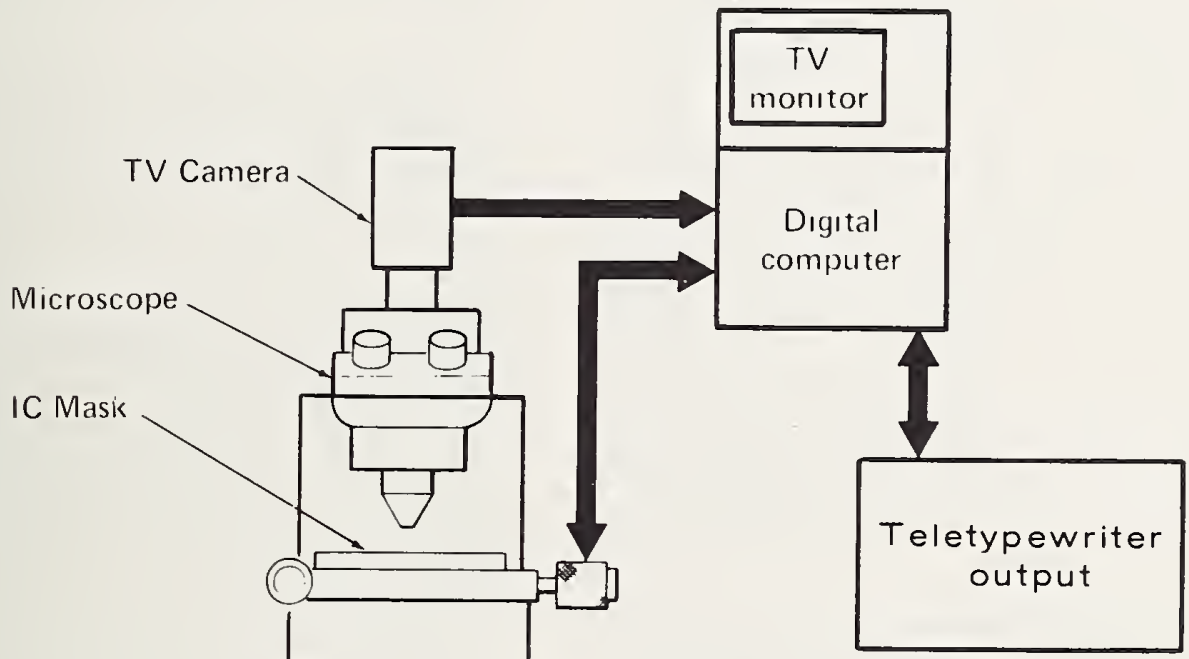

Figure 4. Block diagram of TV-microscope automatic mask inspection system.

Table 3 - Critical Parameters for TV-Microscope Mask Inspection Systems with a 20 - by $20-\mathrm{mm}$ Image Tube Target.

\begin{tabular}{ccccccc}
$\delta, \mu \mathrm{m}$ & $\mathrm{NA}_{\mathrm{min}}$ & $\mathrm{M}_{\mathrm{obj}}$ & $\mathrm{s}, \mathrm{mm}$ & $\mathrm{M}_{\text {tot }}$ & $\mathrm{R}_{\mathrm{r}}, \mu \mathrm{m}$ & $\ell, \mathrm{mm}^{-1}$ \\
\hline 2 & 0.33 & $10 \mathrm{X}$ & 0.8 & $25 \mathrm{X}$ & 50 & 20 \\
4 & 0.16 & $10 \mathrm{X}$ & 0.8 & $25 \mathrm{X}$ & 100 & 10 \\
2 & 0.33 & $5 \mathrm{X}$ & 1.6 & $12.5 \mathrm{X}$ & 25 & 40 \\
4 & 0.16 & $5 \mathrm{X}$ & 1.6 & $12.5 \mathrm{X}$ & 50 & 20 \\
\hline
\end{tabular}


The resolution of the TV tube and its modes of operation are dependent on the tube design and construction. Both vidicon and image dissector tubes are compatible with this technology and each offers different advantages.

The target of the vidicon tube is coated with a photoconductive coating such as antimony trisulfide or lead oxide. This target is given a uniform negative charge by sweeping an electron beam across it; when a light image is projected on the target, the resultant charge loss on the target coating is proportional to the light intensity.

This charge pattern is retained on the target; a sweeping electron beam recharges the screen. The beam current necessary to recharge an area of the screen and the coordinates of the recharged area provide data that are digitized and read into a computer. In this image data gathering process, the charge pattern is erased. Before data on a new target image can be taken, it is necessary for the target to be uniformly charged. Consequent1y, the entire target area must be swept a second time by the electron beam before a new image is projected onto it. The tube cycle time is the sum of the time necessary to read the charge pattern information and the time necessary to completely erase the previous image. One property of the vidicon is that the target charge pattern remains after the target illumination ceases. Thus, stroboscopic techniques may be used with this tube.

The image dissector tube target is coated with a photocathode material, generally some combination of sodium, potassium, cesium, and antimony. When a spot of light strikes the target, electrons are released and are focused onto an anode plate containing an aperture. A deflection field is applied, and photoelectrons from various areas are selectively made to pass through this aperture. The current passing through this aperture is amplified and recorded as a function of the location of the emitting target area by a computer. Unlike the vidicon, this tube has no image storage capability and the image disappears immediately when the target illumination ceases; consequently, stroboscopic techniques cannot be used with this tube. This tube offers the flexibility of randomaccess scanning that can be interfaced with a computer programmed to recognize particular features in a scan and automatically analyze these features in greater detail [6]. Electronic zoom is also possible with this tube by changing the scan amplitude or frequency. Image dissector tubes are available with a matrix of 2000 by 2000 resolvable points that are scanned at the rate of 0.5 microseconds per point or 2 seconds per complete target scan. These tubes are not used in conventional raster-scanned TV applications because of their illumination requirements which are $10^{3}$ to $10^{6}$ times greater than vidicons.

The rate at which the image information can be read from these targets is a function of the time required to scan the target. The standard (U.S.) television picture contains a nominal 525 lines which are scanned 30 times a second. The advantage of using this scan rate is the economics of system construction; there is a myriad of commercial electronic equipment that is designed to operate at this scanning rate. The use of a different scanning rate or a different number of scanning lines is possible, but may involve the design and construction of special equipment.

The resolution of the TV tube is a function of the target coating, the spot size of the scanning beam for a vidicon or aperture size for image dissector, and the number of scan 1ines. The size of the scanning spot or aperture is a major factor in the ability to read the detail in the target image. Any defect smaller than the spot is read as if it were spread over the same area as the spot, with correspondingly less intensity. If two defects in the target image are separated by a distance of one spot diameter or less, the tube signal may not drop below the threshold between the spots and they may not be recognized as separate.

A criterion for defect detection is that the spacing between successively scanned lines be equal to or smaller than the tube image of the smallest defect to be detected. This spacing can be equated to the spot size. Since the entire target area is scanned in 525 lines, the spot size or tube resolution, $R_{t}$, is given by

$\mathrm{R}_{\mathrm{t}}=\mathrm{H} / 525$,

where $\mathrm{H}$ is the dimension of the target in the direction perpendicular to the scan. The value of $R_{t}$ must be equal to or less than $R_{r}$.

The value of $R_{t}$ may be used to estimate the misalignment tolerance, D. A straight edge parallel to the tube scanning direction will be interpreted as a defect if its image appears at a distance perpendicular to the scanning direction that is greater than $R_{t} / 2$ from where it is programmed to appear. Similarly, a misalignment of an edge perpendicular to the scan direction that is misaligned by more 
than $R_{t} / 2$ in the scan direction will also be interpreted as a defect if the tube resolution in each direction is the same. This image misalignment is converted to a feature misalignment tolerance on the photomask through the optical magnification of the microscope to give,

$D<R_{t} / 2 M_{\text {tot }}$.

Scanning the mask on a stage through successive fields of view under a microscope is accomplished most rapidly by accelerating the stage through a distance approximately one half the edge dimension of the field of view and decelerating the stage through the remaining distance to the next field of view so that it stops precisely positioned. The stage may be designed so that the natural frequency of the table moving as a rigid body on its ways as a result of elastic deformation is tuned to the applied torque of the motor and time of traverse [7]. When this tuning is accomplished, the stage vibration is negligible when the table stops $[7,8]$.

The time required to inspect the mask is the complete cycle time multiplied by the number, $\mathrm{N}$, of fields of view. The complete cycle time is the sum of the time it takes to index to the next field of view plus the tube cycle time, if these steps are done sequentially. A comparison is given in table 4 of the times required to scan a 76- by 76-mm field with a vidicon tube with a 10- by $10-$ $\mathrm{mm}$ target area and with an image dissector tube with a $25-$ by $25-\mathrm{mm}$ target area. In making the calculations it was assumed that the optical magnification was $25 \mathrm{X}$, that the stage acceleration was $4.9 \mathrm{~m} / \mathrm{s}^{2}$, and that the distances for acceleration and deceleration were equal.

The shortest inspection time shown in table 4 is long compared to the time of about $15 \mathrm{~min}$ which is typically allowed for an inspector to inspect the same mask [2]. However, it should be emphasized that an inspector only partially inspects the mask and relies on sampling statistics for quality control. The automated inspection system does a 100- percent pattern inspection on all of the arrays in the mask.

For this system to operate using either a vidicon or an image dissector tube, the signal change on going from a transparent to opaque area must be large enough that an electronic threshold setting can distinguish between them. This places restrictions on both the signal-to-noise ratio of the TV tube and on the resultant modulation transfer function (MTF) of the microscope and TV tube. If the resultant MTF is too low, the system cannot distinguish between the clear and opaque areas and an erroneously low defect count may result. If the signal-to-noise ratio is not sufficiently low, an erroneously high defect count may result.

Applications - Equipment has been constructed using this technology and a vidicon tube capable of counting pinholes and spots in masks which have device geometries with $2.5-\mu \mathrm{m}$ line widths $[9,10]$. The combined optical and electronic magnification is $250 \mathrm{X}$ with a $10 \mathrm{X}$ objective. The pinhole and spot counter operates with a fixed field of view which requires that the stage holding the mask be indexed in fixed increments. The equipment is capable of inspecting masks for wafer sizes up to 2 in. $(5 \mathrm{~cm})$ in diameter. In operation, defects are counted as many times as they are intercepted by the TV camera scan line. The size of the smallest defect counted is a function of the smallest mask geometry. The electronics were designed so that defects are counted which are approximately 80 percent or more of the size of the smallest line width on the mask. A complete indexing cycle occurs every $8 / 30 \mathrm{~s}$. The indexing cycle consists of $1 / 30 \mathrm{~s}$ for information reading, $3 / 30$ $\mathrm{s}$ for indexing, and $4 / 30 \mathrm{~s}$ for complete tube erasure.

With such a system, a 100-percent inspection of a 76- by 76-mm mask with a field of view of 0.8 by $0.8 \mathrm{~mm}$ would require about $39 \mathrm{~min}$. This time could be shortened to about $13 \mathrm{~min}$ by using stroboscopic "flash on the fly" illuminations of $10 \mu \mathrm{s}$ for every field of view in conjunction with a stage velocity of 8 $\mathrm{mm} / \mathrm{s}$. This velocity permits a $1 / 30-\mathrm{s}$ scan

Table 4 - Scan Times for Two State-of-the-Art TV-Microscope Mask Inspection Systems.

\begin{tabular}{cccccccc}
\hline Tube & s, mm & $\begin{array}{c}\text { Scan } \\
\text { time, ms }\end{array}$ & $\begin{array}{c}\text { Index } \\
\text { time, ms }\end{array}$ & $\begin{array}{c}\text { Erase } \\
\text { time, ms }\end{array}$ & $\begin{array}{c}\text { Total Cycle } \\
\text { time, ms }\end{array}$ & N & $\begin{array}{c}\text { Inspection } \\
\text { time, min }\end{array}$ \\
\hline $\begin{array}{c}\text { Vidicon } \\
\begin{array}{c}\text { Image } \\
\text { Dissector }\end{array}\end{array}$ & 0.4 & 33 & 18 & 33 & 84 & 35000 & 49 \\
\hline
\end{tabular}


for information and an additional two $1 / 30-\mathrm{s}$ scans for every erasure. This 13-min inspection time includes about 1 min for stage reversals and indexing. These modifications are within the current state-of-the-art using vidicons with more sensitive target coatings and stages that can operate and index to the required accuracy [8].

The speed of the system using an image dissector tube can also be improved. In princi$\mathrm{ple}$, it is possible to construct a dissector tube using a 4 by 4 matrix of apertures, a1though construction of such a tube would be very expensive. This tube would scan a single field of view in $1 / 16$ of the time now required. This would decrease the total inspection time per mask to less than 12 min. The inspection time could be reduced further by exploiting the random scanning capability and the programmable features of the image dissector tube to examine only the critical portions of the patterns on the mask. These features also would enable detailed examination of defects as they are scanned which is necessary for defect identification, but this is done by sacrificing inspection speed. These operations are normally not possible with a vidicon.

\subsection{Spatial-Filtering Method}

Principles of Operation - This method [11] is based on the lens property that for coherent light the Fraunhofer diffraction pattern of the object, which is represented by the Fourier transform of the object, is produced at the focal plane of the radiation source. Therefore, if a photomask is placed in front of a lens and illuminated by a collimated laser beam, the Fourier pattern of the object is produced behind the lens at the transform plane located by the focal length [12]. A second lens may be used to produce a diffraction pattern of this Fourier transform and thereby perform an inverse transform reconstructing the original image. Another lens property exhibited by this arrangement is that the diffraction pattern is invariant to translating the mask in the object plane, provided that the rotational orientation and focal position of the mask are maintained.

The simplest means of applying these physical properties to mask inspection $[13,14]$ is to construct a spatial filter which is inserted at the Fourier transform plane. If this filter only blocks the diffraction pattern produced by the periodic die arrays, any diffraction pattern produced by nonperiodic defects will pass through the filter and the reconstructed image will consist of only the defects.
Analysis - This method is substantially different from the previous methods in that each die is inspected in toto instead of being scanned. The inspection of each die is manually made by inspecting the filtered and reconstructed image of each die showing only its defects. Each such inspection is made for all of the 196 respective dice. A mask inspection time of about $7 \mathrm{~min}$ is obtained if it is assumed that about $2 \mathrm{~s}$ is required to inspect each die.

Spatial-filtering techniques are sensitive to surface and thickness irregularities in the glass photomask substrate as well as to changes in the refractive index of the glass. An appreciation for this sensitivity may be obtained by considering the number $\mathrm{N}_{\lambda}$ of radiation wavelengths in the glass given by $\mathrm{N}_{\lambda}=$ $\xi \mathrm{n} / \lambda$ where $\lambda$ is the wavelength of radiation in a vacuum, $\xi$ is the thickness of the glass, and $\mathrm{n}$ is the refractive index of the glass. The variation of the number of wavelengths in the glass $\Delta \mathrm{N}_{\lambda}$ is given by

$$
\Delta \mathrm{N}_{\lambda}=[\xi \Delta \mathrm{n}+\mathrm{n} \Delta \xi] / \lambda \text {. }
$$

Assuming that $\mathrm{n}=1.5, \xi=60 \mathrm{mils}(1524 \mu \mathrm{m})$, and $\lambda=0.5 \mu \mathrm{m}$, it is easy to show that either pair of values $\Delta \mathrm{n}=1.6 \times 10^{-4}, \Delta \xi=0$ or $\Delta \mathrm{n}=0, \Delta \xi=0.17 \mu \mathrm{m}$ will change $\Delta \mathrm{N}_{\lambda}$ by $1 / 2$ shifting the phase of the emerging wavefront by $180^{\circ} \mathrm{C}$. This, in turn, causes unwanted destructive interference in the reconstructed wavefront precluding the expected interference effects. Although the surface irregularity problems can be alleviated through the use of a liquid gate, namely, creating an even surface by covering the surface of the substrate with a liquid film of matching refractive index, this creates contamination and cleaning problems which may be more severe than the original defect problems. In addition, it is both difficult and time consuming to make adequate filters [2]. These techniques are further hampered by focusing problems and difficulties encountered in registering the filter with the transformed image.

Applications - Watkins [15] modified this technique by using two apertures to restrict the illuminated mask surface; the resultant diffraction pattern is further filtered by a grating prior to reconstruction of the image. By choosing the aperture separation to be a multiple of the step-and-repeat distance, the Fourier transforms from two die patterns can be made to subtract from each other, resulting in an image consisting only of the diffraction patterns produced by random defects and step-and-repeat errors. This tech- 
nique is also independent of mask translations in the object plane, but is dependent on mask and die pattern rotations. It is estimated [15] that this technique is sensitive to defects of $5-\mu \mathrm{m}$ diameter and stepand-repeat errors of $3.8 \mu \mathrm{m}$.

A variation of the above techniques, which is capable of detecting irregularly shaped defects as small as $2.5 \mu \mathrm{m}$, has been described by Axelrod [16]. In this technique the diffraction pattern is filtered with a filter approximating the form factor or envelope function for the intensity in the Fourier transform plane. For a mask with rectangular features, the width of the diffraction pattern in the transform plane is determined by the narrowest features. The diffraction pattern from an illuminated circuit pattern with rectangular geometry will have the overall appearance of a tapered cross due to the form factor from the perpendicular lines within one die pattern. The diffraction pattern from a defect will extend over a much broader area because of either the small size of the defect or the jagged nature of the edges of larger defects. Thus, a filter consisting of a cross simulating the form factor placed in the transform plane will suppress regular features and display defects in the reconstructed image. This technique does not require as stringent registration between the filter with the transformed image as those techniques previously described.

A mask inspecting device utilizing the method of Axelrod [16] has been described by Minami and Sekizawa [17]. This device incorporates a green incoherent light which superimposes the image of the mask pattern over the image of the reconstructed defects. This superposition of images enables the operator to distinguish spots in the reconstructed image produced by the corners of the mask pattern from defects which are circular in character. The resultant image is viewed through a microscope and enables the operator to identify the respective locations of defects in the die pattern. The analysis of this device [17] indicates that the translational setting tolerance of the filter is in excess of $10 \mathrm{mils}(0.25 \mathrm{~mm})$ and that defects as small as $0.5-\mu m$ diameter should be detectable. Focusing requirements are not analyzed.

\subsection{Dual-Beam, Flying-Spot-Scanner Method}

Principles of Operation - In this method two spots of light produced by focusing a laser beam are simultaneously scanned over corresponding portions of two die patterns on the same photomask. Differences between the transmittance of these two light spots are interpreted as defects.

Analysis - A published analysis of this method was based on the detection of a square 2by $2-\mu \mathrm{m}$ defect and assumed a Gaussian distribution of the intensities of the scanning spots [3]. A spot of 3- $\mu \mathrm{m}$ diameter was determined to be sufficient for the detection of $2-\mu \mathrm{m}$ defects. The spot edge was arbitrarily defined at the point where the intensity dropped to a value of $1 / e^{2}$ of the maximum intensity. The minimum misalignment $\mathrm{D}$, in micrometers, that could be tolerated between two die patterns and give an adequate signalto-noise ratio without giving rise to the detection of spurious defects was derived as

$\mathrm{D} \approx 0.4 \mathrm{w}_{\mathrm{o}}$,

where $W_{O}$ is the radius of the scanning spot in micrometers. For a $3-\mu \mathrm{m}$ spot ( $W_{0}=1.5$ $\mu \mathrm{m})$ this relation predicts a permissible misalignment of $0.6 \mu \mathrm{m}$ which is comparable to the optical-overlay method. The time required to scan a $50-$ by $50-\mathrm{mm}$ photomask was reported to be about 3 min which scales to about 7 min for a 76 - by 76-mm mask.

Applications - This system [3] is able to recognize the differences between surface defects on the mask, such as dust, and intrinsic defects. This is done by placing four small fiber optic bundles in four quadrants at $45 \mathrm{deg}$ to the principle axes of the mask and $60 \mathrm{deg}$ to the optical axis of the reduction lens. The four bundles are brought together at a second photodetector; the output of this detector is registered if it exceeds a certain threshold and identifies the defects as surface defects. This technique of surface defect detection should also be adaptable to the optical-overlay method.

The method can also be used for line-width measurements through the operation of the system in a "microdensitometer" mode [3]. This is done in a single spot-scan mode and the transmittance profile of each of the two opposite edges of a feature, such as a line, are recorded as a function of position. In this system, the edges are located at the 0.5 transmittance points. Measurement errors resulting from the use of this criterion for edge location are discussed in section 3 . 
Dimensional inspection is the measurement of photomask die pattern feature dimensions. These measurements are of two types, referred to as line-width measurements and run-out measurements. The accuracy of each of these measurements is dependent upon the location accuracy of the line or feature edge. The $\mathrm{mi}$. crodensitometer is designed to measure the transmittance of a small area as a function of position and is well suited to dimensional measurements. The application of the optical-overlay, TV-microscope, and dualbeam laser-scanning methods to dinensiona]. inspection essentially consists of operating any of these respective inspection systems as a microdensitometer. Because dimensional inspection is a potentially important application of the microdensitometer, the principles which govern the operation of a microdensitometer in measuring accurate data are reviewed. Criteria for line-edge location are also presented; these differ according to whether the microdensitometer is operating with coherent or incoherent illumination. Since the operation of a dual-beam laserscanning system, with coherent illumination, was briefly mentioned in section 2.4, 1ineedge location using coherent illumination is first discussed.

\subsection{Line-Edge Location}

A model of a line edge with a sloping (nonideal) physical edge and transmittance profiles produced by scanning coherent light spots of 1-, 2-, and 3- $\mu \mathrm{m}$ diameter across the line edge is used to illustrate the principles involved in choosing the edge 1ocation. Details of this model and associated calculations are given in the appendix. The physical profile of the line edge is similar to those observed for chromium maslis in the NBS line-width measurement program [18]; the edge is inclined at an angle of $55 \mathrm{deg}$ from the horizontal until the full film thickness is reached. Gaussian functions were used to represent the intensity distribution of the light spots instead of the actual one-dimensional impulse response functions because mathematically they are much easier to work with. The calculated transmittance profiles in figure 5 show that an invariant point, i.e., a point that is common to all transmittance profiles regardless of the scanning spot size, exists at the transmittance $\mathrm{T}_{c}$ determined from the relation

$$
\mathrm{T}_{\mathrm{C}}=0.25\left(1+\sqrt{\mathrm{T}_{\mathrm{o}}}\right)^{2},
$$

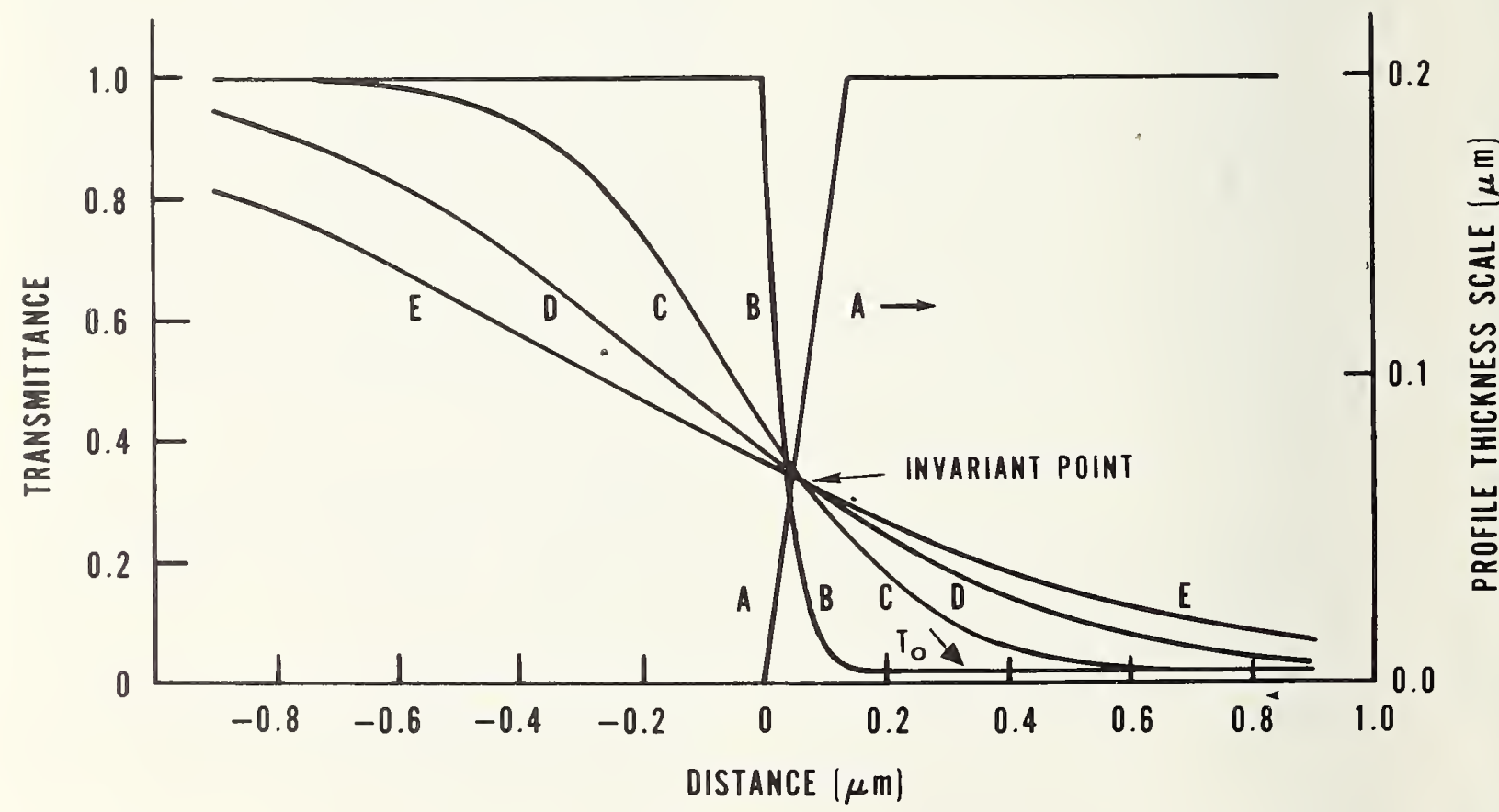

Figure 5. Line-edge profiles for coherent radiation showing: A, the physical profile; B, the transmittance of edge A; C, D, and E are transmittance profiles of edge A obtained by scanning with coherent Gaussian light spots of 1-, 2-, and 3- $\mu \mathrm{m}$ diameters, respectively. The invariant point is located by $\mathrm{T}_{C}=0.325$ for the case where $\mathrm{T}_{0}=0.02$. 
Table 5 - Comparison of Total Edge Offset for a Line-Width Measurement When the Edges are Located at the Invariant Point and the 0.5 Transmittance Point, Respectively.
Spot Diameter, $\mu \mathrm{m}$
1
0.24
2
0.44
3
0.66

where $T_{O}$ is the transmittance of the full thickness of the film. This relation was first derived by Nyyssonen [19] for ideal (vertical) physical line edges and is seen to be applicable to this model with a nonideal edge. From figure 5 , measures of the offset between the invariant point and the edge positions located by the 0.5 transmittance point are obtained. These offsets multiplied by 2 represent the total offsets from the invariant point that would be obtained in a line-width measurement based on the 0.5 transmittance point. These total offsets are a function of the spot size used and are listed for various spot sizes in table 5. These offsets are representative of those that may be expected between linewidth measurements made by locating the line edge at $\mathrm{T}_{\mathrm{c}}$ given by eq (13) and measurements made by locating the line edges at the 0.5 transmittance point as described in section 2.4 for the coherent dual-beam, flying-spot scanner [3]. It may also be seen from figure 5 that a difference of $0.4 \mu \mathrm{m}$ would result between measurements of the same line width made on the same microdensitometer using coherent spot sizes of $1-$ and $3-\mu \mathrm{m}$ diameter and locating the edge at the 0.5 transmittance point.

This model does not apply directly to "see through" masks since it does not account for edge ringing that is observed or other phase effects that occur with these masks; such effects have been described elsewhere $[19,20]$.

A similar model and calculations can be used to calculate transmittance profiles for incoherent illumination. The calculated profiles are similar to the coherent profiles except that the invariant point is located at a transmittance given by $0.5\left(1+\mathrm{T}_{0}\right)$.

\subsection{Criteria for Microdensitometer Operation}

The microdensitometer is an instrument that is designed to measure the optical density of, or the transmittance through, small areas as a function of position. Figure 6 shows a schematic diagram of a mask inspection system consisting of a microdensitometer interfaced with a digital computer. An area of the photomask is illuminated by the system influx optics consisting of a source, a source condenser, a source aperture, an influx ocular, and an influx objective. The light transmitted through the mask is collected and measured by the system of efflux optics. The amount of light entering through the sensor aperture is measured by a photomu1tiplier. The photomultiplier output data are digitized and recorded in a computer memory along with the corresponding positional information.

The microdensitometer can be used in either an underfulling or an overfilling mode and operated in either a sample scanning or an image scanning configuration. The operational mode depends upon the relative selection of the numerical apertures of the influx objectives, $\mathrm{NA}_{I}$, and the efflux objective, NAE; overfilling occurs when $\mathrm{NA}_{I}>\mathrm{NA}_{\mathrm{E}}$, while underfilling occurs in the case where $\mathrm{NA}_{\mathrm{I}}<\mathrm{NA}_{\mathrm{E}}$. The sample scanning configuration is achieved when the source aperture is imaged on the sample and the efflux optics merely serve to gather the transmitted light; the size of the scanning light spot is smaller than the geometrical projection of the sensor aperture through the efflux optics onto the sample plane. In this sample scanning configuration the resolution is determined by the minimum or smallest resolvable spot, which is essentially the width, $W$, of the impulse response of the lens and is given by the relation

$\mathrm{W} \approx \lambda / \mathrm{NA}$

where $\lambda$ is the wavelength of light.

The image scanning configuration is realized when the illuminating spot on the sample plane is larger than the geometrical projection of the sensor aperture through the lens on to the sample plane. In the image scanning configuration the resolution is limited by the resolution of the efflux objective.

The following discussion assumes diffractionlimited, aberration-free optics with no defocus. Table 6 summarizes the minimum image width, depth of focus, and resolution limit in cycles/mm as a function of NA for light of 500-nm wavelength.

It must be stressed that the microdensitometer must be operated in a manner such that analytically representative mapping of the optical density is obtained. The ability to 


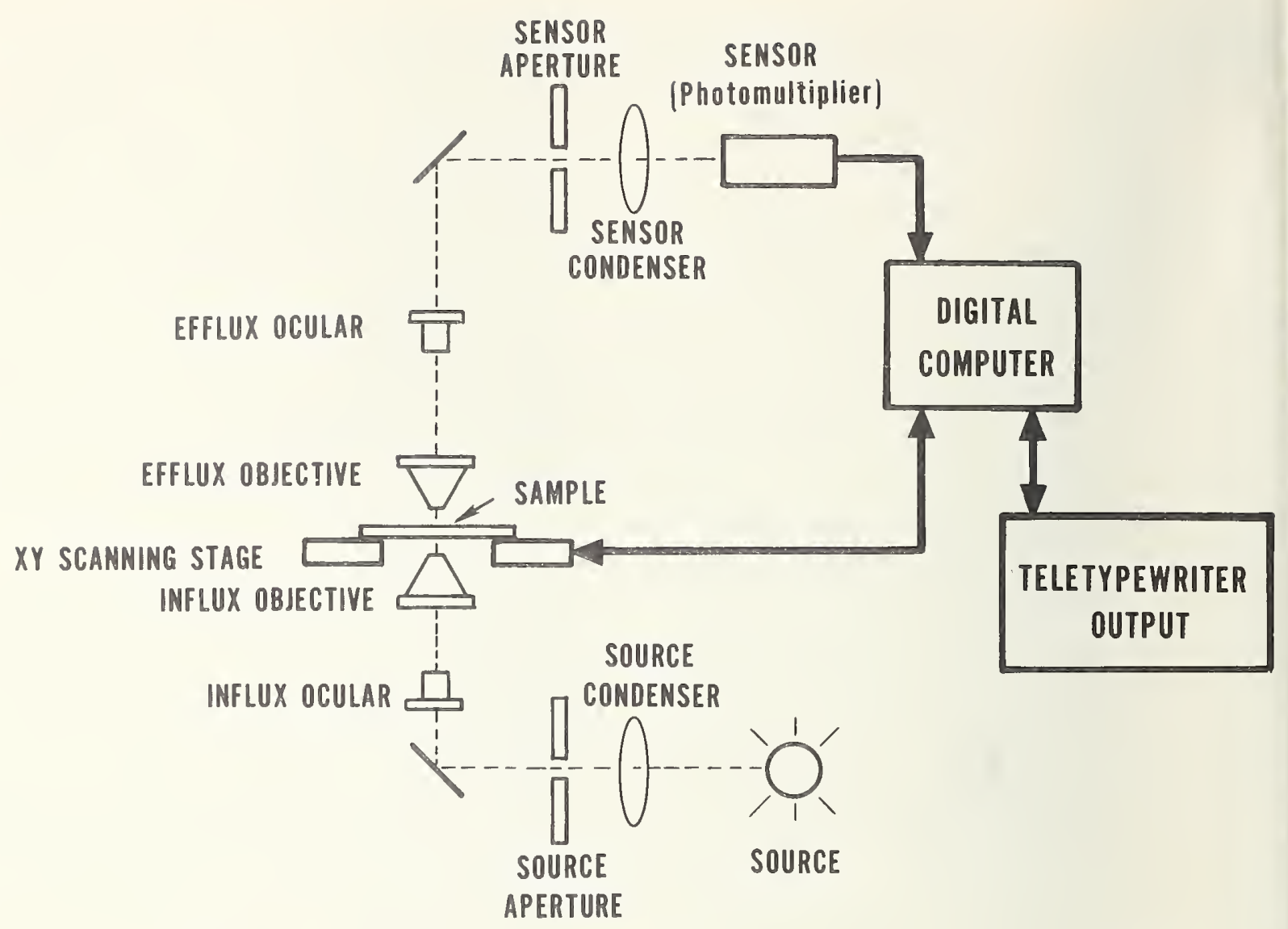

Figure 6. Schematic of a microdensitometer-digital computer mask inspection system.

\begin{tabular}{cccc} 
Table $6-\begin{array}{c}\text { Calculated Values of Lens Parameters Dependent } \\
\text { on Numerical Aperture, for Diffraction-Limit } \\
\text { Optics at a Wavelength of } 500 \mathrm{~nm}[21]\end{array}$ \\
\hline NA & $\begin{array}{c}\text { Minimum Image } \\
\text { Width, } \\
\mu \mathrm{m}\end{array}$ & $\begin{array}{r}\text { Depth of Focus, } \\
\mu \mathrm{m} .\end{array}$ & $\begin{array}{c}\text { Resolution } \\
\text { Limit, } \\
\text { cycles/mm }\end{array}$ \\
\hline 0.08 & 6.2 & 39 & 320 \\
0.10 & 5 & 25 & 400 \\
0.16 & 3.1 & 9.8 & 640 \\
0.25 & 2 & 4 & 1000 \\
0.30 & 1.7 & 2.8 & 1200 \\
0.40 & 1.25 & 1.5 & 1500 \\
0.50 & 1 & 1 & 2000 \\
0.65 & 0.8 & 0.6 & 2600 \\
0.85 & 0.6 & 0.35 & 3500 \\
1.00 & 0.5 & 0.25 & 5000 \\
\hline
\end{tabular}


fully characterize the data obtained from a microdensitometer depends on its operation in either a coherent light regime or an incoherent light regime.

A microdensitometer system'designed and built for the accurate measurement of line widths less than $10 \mu \mathrm{m}$ has recently been described [19]. This system operates in an underfilled mode with $\mathrm{NA}_{I} / \mathrm{NA}_{E}=0.6 / 0.9$, uses filtered coherent light of $530-\mathrm{nm}$ wavelength, scans at a very slow constant speed of a few micrometers per second, has a scanning stage translational accuracy of $0.01 \mu \mathrm{m}$, locates the line edge at a transmittance given by $0.25\left(1+\sqrt{\mathrm{T}_{\mathrm{O}}}\right)^{2}$, and is capable of line-width measurements with a three-sigma standard deviation less than $0.05 \mu \mathrm{m}[18]$. This instrument derives its accuracy from the stage translational accuracy and the high degree of analytical characterization of the data.

Incoherent illumination is more commonly used for microdensitometer operation. In the incoherent regime, analytical characterization of the data depends on linear microdensitometer operation. When a microdensitometer is operating linearly, the line-edge location or invariant point is a function of the background transmittance $\mathrm{T}_{\mathrm{O}}$ and is located at a transmittance threshold of $\mathrm{T}_{\mathrm{C}}=0.5\left(1+\mathrm{T}_{\mathrm{O}}\right)$. Swing [21] has derived criteria for the linear operation of a microdensitometer in the incoherent light regime. Compliance with these criteria assures that the microdensitometer response is characterized by the linear relation

$$
\tilde{I}(\sigma)=\tilde{I}_{0}(\sigma) \tau(\sigma)
$$

where:

$$
\begin{aligned}
\tilde{I}(\sigma)= & \text { the spectrum of the image inten- } \\
& \text { sity as a function of the spatial } \\
& \text { frequency } \sigma, \\
\tilde{I}_{0}(\sigma)= & \text { the spectrum of the objective in- } \\
& \text { tensity, and } \\
\tau(\sigma)= & \text { the optical transfer function of } \\
& \text { the system. }
\end{aligned}
$$

The criteria derived by Swing are:

$$
\begin{aligned}
& \text { overfilling [21]: } \frac{\mathrm{NA}}{\mathrm{NA}} \geq 1+\frac{\eta_{O}}{\sigma_{0}} \text {, and } \\
& \text { underfilling [22]: } \frac{\mathrm{NA}_{\mathrm{E}}}{\mathrm{NA}} \geq 1+\frac{\eta_{\mathrm{O}}}{\kappa_{\mathrm{O}}}
\end{aligned}
$$

where $\sigma_{0}$ and $\kappa_{0}$ are the resolution limits of the efflux and influx objectives in terms of a maximum spatial frequency and are equal to $2 \mathrm{NA}_{\mathrm{E}} / \lambda$ and $2 \mathrm{NA} I / \lambda$, respectively, and $\eta_{0}$ is the upper frequency limit in the sample. The parameter, no, is unambiguously defined only for a sample consisting of a grating with an intensity profile represented by a sine function of frequency, no. This situation does not occur when the scanned sample is a photomask. Photomasks consist of functional patterns containing line edges with extremely acute optical density gradients. Such edges may be thought of as being composed of a superposition of intensity profiles represented by sine functions of different spatial frequencies, $\sigma$. The collective group of all of these spatial frequencies makes up the image spectrum $\tilde{I}(\sigma)$. The sharper the line edge, or more acute the density gradient, the more high frequency components are present in the spectrum. Consequently, the greater the limiting frequency, $n_{0}$, that a microdensitometer responds to linearly, the more accurate is the measurement of the optical density edge gradient and the more precise is the edge 1ocation.

An image that accurately represents the edge profile must be measured by the microdensitometer to locate line edges on photomasks with the precision and accuracy required in the microelectronics industry. There is little reason to expect that an accurate representation of an edge profile will be measured if the optics are chosen so that either the ratio of $N A_{I} / N A_{E}$ for the overfilling case, or the ratio of $\mathrm{NA}_{E} / \mathrm{NA}_{I}$ for the underfilling case has a low value. This is because the nonlinear measurement of the high frequency components of the edge contribute to the edge image profile in a way that can unpredictably distort the image. If this profile is not an accurate representation of the actual edge profile, the computed edge location will be in error. Furthermore, nonlinear response to high frequencies can yield unpredictable changes in the measured edge profiles with slight changes in the edge gradients; this effect precludes accurate edge location. Consequently, linear microdensitometer operation over the greatest practicable frequency range must be achieved. Linear operation cannot be assured unless the criteria of eqs (15) and (16) are satisfied. In particular, nonlinear response always occurs when the numerical apertures of the efflux and influx objectives are matched. Matching numerical apertures is common practice and recommended by some microdensitometer manufacturers. 
The maximum spatial frequencies, $\eta_{0}$, for linear response at 500-nm wavelength calculated from the criteria of eqs (15) and (16) are given in table 7 for various numerical apertures. Caution should be exercised in the blind application of these values since nonlinear response may exist for special cases even when these criteria are satisfied.

Such a case could result from the use of large numerical aperture objectives with the sample resting on a glass platen. The diffraction angles associated with the very high frequency information are large and at these large angles, it is possible for total reflection to occur from a glass platen or photomask. This total reflection precludes the passage of the energy associated with some frequencies below the calculated lens cutoff and has the effect of limiting the numerical aperture of the affected objective.

A final consideration of the optical limitations of the microdensitometer is that of incoherence at the source aperture. The criteria of eqs (15) and (16) are derived on the assumption of incoherent illumination at the source aperture. This is impossible to achieve exactly, but conditions can be speci- fied for which the illumination can be considered effectively incoherent [23]. The fundamental criterion that must be satisfied is

$\frac{\text { source aperture width }}{\text { coherence interval }} \geq 4+Q\left(n_{0}+\sigma_{0}\right)$

where $Q$ is the width of the reduced source aperture projected onto the sample. This criterion must be satisfied for both underfilling and overfilling when image scanning is employed. When sample scanning is employed, the optics should be chosen so the size of the scanning light spot, $W$, is limited by the numerical aperture of the influx objective, and its width is given by eq (14). When this is done, the coherence interval is effectively the width of the Airy disk. The light spot can be made no smaller; decreasing the source aperture width further will change neither the coherence interval nor the size of the illumination on the sample. Under these conditions, this system is independent of the coherence existing at the source aperture and the source can be a laser, an arc lamp, an incandescent light bulb, etc. [21];

Table 7 - Calculated Maximum Spatial Frequencies for Linear Response at $500 \mathrm{~nm}$ [21].

$\begin{array}{llccc}\mathrm{NA}_{\mathrm{I}} & { }^{\mathrm{NA}} \mathrm{E} & \frac{{ }_{\mathrm{I}}}{\mathrm{NA}_{\mathrm{E}}} & \begin{array}{c}\eta_{0}, \\ \text { cycles } / \mathrm{mm}\end{array} & \begin{array}{c}\sigma_{0}, \\ \text { cycles } / \mathrm{mm}\end{array}\end{array}$

(a) Overfilling (eq (15))

\begin{tabular}{lllcc}
\hline 0.85 & 0.50 & 1.7 & 1400 & 2000 \\
0.65 & 0.40 & 1.625 & 1000 & 1600 \\
0.50 & 0.25 & 2.0 & 1000 & 1000 \\
0.40 & 0.25 & 1.6 & 600 & 1000 \\
0.25 & 0.16 & 1.56 & 360 & 640 \\
\hline & & $\mathrm{NA}_{\mathrm{E}}$ & $\eta_{0}$, & $\mathrm{K}_{0}$, \\
$\mathrm{NA}$ & $\mathrm{NA}$ & $\mathrm{NA}_{\mathrm{I}}$ & cycles/mm & cycles $/ \mathrm{mm}$ \\
\hline
\end{tabular}

(b) Underfilling (eq (16))

\begin{tabular}{lllrl}
\hline 0.65 & 1.0 & 1.54 & $1400 *$ & 2600 \\
0.40 & 0.65 & 1.63 & $1000 *$ & 1600 \\
0.25 & 0.50 & 2.0 & $1000 *$ & 1000 \\
0.25 & 0.40 & 1.6 & $600 *$ & 1000 \\
0.65 & 0.85 & 1.3 & $780 *$ & 2600 \\
\hline * See [22]. & & &
\end{tabular}


However, the criteria of eqs (15) and (16) must still be satisfied for linear operation.

Measurements of the coherence functions existing at the source aperture plane of four different microdensitometers were made at the National Bureau of Standards with the aid of a wavefront shearing interferometer [24]. The coherence intervals varied from 20 to 30 $\mu \mathrm{m}$; the average was approximately $24 \mu \mathrm{m}$. On those microdensitometers employing a single element (a microscope objective) on the influx side, the criterion of eq (17) could not be satisfied. For those instruments in which an ocular was coupled with the influx objective, this criterion was easily satisfied. This substantiates the statement by Swing [21] that the influx optics should employ as large a reduction as practical.

Microdensitometers with low reduction factors may cope with the problem of achieving effective incoherence by operating in a sample scanning configuration using the smal1est scanning numerical aperture possible. This will also reduce the problems with flare light, leaving as the only uncertainty the actual size of the sampling aperture which is difficult to measure and varies as the optical density it traverses [21]. This introduced uncertainty is less than the one replaced, and represents a "best" condition for such a microdensitometer.

Flare light is any unwanted or stray light in the image. It may appear in or out of focus and has always been manifested in microscope systems. The problems caused by flare light worsen as sample frequencies get higher and may mask nonlinearities by reducing contrast in the image and smoothing-out the telltale signs of nonlinear response such as edge ringing. In a microdensitometer as much as 1 -percent flare light can degrade the image of a we11-defined edge, whose optical density goes from 0 to 3.0 , beyond the point where useful information can be obtained from it [21].

It may be concluded that the optical design of a microdensitometer should be carefully considered when this instrument is applied to photomask inspection. The choice of an operation configuration such as image scanning or sample scanning using either overfilling or underfilling must be carefully evaluated with respect to the particular application for which the instrument is intended. Difficulties may be encountered when applying this instrument to scanning highly reflective chromium masks because stray light may be reflected into the microdensitometer and cause flare.

\subsection{Applications to Mask Inspection}

A microdensitometer with a stage scanning speed of up to $30 \mathrm{~mm} / \mathrm{s}$ has been described for the automatic inspection of mask registration and critical dimensions [25]. This system uses both an efflux objective and influx objective with $N A=0.25$, locates the line edge at the transmittance $\mathrm{T}=0.5$, and has a stage location precision of $1 \mu \mathrm{m}$. This system does not satisfy the various criteria for accurate measurements as discussed above. Welford [26] has calculated edge profiles for the case of matched influx and efflux numerical aperture objectives. These calculations clearly show that the edge profile obtained is neither that for the coherent nor incoherent regimes. The low value of the numerical aperture itself may preclude the observation of significant sample data and necessary high-frequency edge components.

The full utilization of the optics may not be realized with this particular system. This is because the response of the associated electronics (which includes the detector, amplifier, and associated circuits) may not satisfy the criterion that the minimum electronic frequency, $f$, for the band pass of the electronic system must be greater than the product of the scanning velocity, $v$, multiplied by the maximum spatial frequency cutoff, $k$, for the scanning system [29]; i.e.,

$\mathrm{f}>\mathrm{VK}$.

Thus, for example, to realize the full resolution of a microdensitometer equipped with an influx objective of $0.65 \mathrm{NA}$ and using 500-nm wavelength illumination (which gives a value of $\kappa_{0}=2600 \mathrm{~mm}^{-1}$ from table 7), and operating at a scanning velocity of $30 \mathrm{~mm} / \mathrm{s}$, the band pass of the electronic system must exceed $78 \mathrm{kHz}$. This implies that the response of the detector $(1 / 2 \pi f)$ must be less than 2 us. Work on line-width measurements with the coherent light system [19] indicates that response times should probably be much less than those calculated here if accurate lineedge location is to be achieved.

While a microdensitometer is suited for photomask dimensional inspection, it is not well suited for the inspection of visual defects. This is illustrated by the following example. If a microdensitometer equipped with a $0.25-$ NA influx objective ( $x_{0}=1000 \mathrm{~mm}^{-1}$ from table 7) is to be used to inspect photomasks for visual defects as small as $2 \mu \mathrm{m}$, the die pattern must be scanned with a $2-\mu \mathrm{m}$ spot in $2-\mu \mathrm{m}$ swaths and data taken at every $2-\mu \mathrm{m}$ interval along the scan. If the stage travels 
at a velocity of $30 \mathrm{~mm} / \mathrm{s}$, a data acquisition rate of $1.5 \times 10^{4}$ words per second is required. This stage velocity also requires a response time $(1 / 2 \pi f)$ less than $5 \mu s$. If these conditions can be achieved, the scan time per individual die pattern, not including stage indexing time, is about $4 \mathrm{~min}$. The total time to inspect the 400 die patterns on the $76-$ by $76-\mathrm{mm}$ mask is about $26 \mathrm{~h}$.

There exists the possibility of reducing this scan time by image scanning with a rectangular aperture. If a 2- by 100- $\mu \mathrm{m}$ aperture is used, the inspection time could be reduced by a factor of 50 to about $32 \mathrm{~min}$. However, with this approach, serious questions arise concerning the response time of the photomultiplier and its ability to make accurate density measurements under these conditions. Furthermore, the integrated intensity over a $2-\mu \mathrm{m}$ scan length is changed by approximately 1 percent for every $0.02 \mu \mathrm{m}$ of misalignment of any transparent to opaque edge extending the length of the aperture. This effect, combined with those from scanning table yaws, die run-out, and other errors commonly found in photomasks, would lead to the detection of copious spurious defects. 


\subsection{Test Masks}

To provide a means for evaluation of various automated mask inspection systems, test photomasks were designed and fabricated with intentional defects. It was intended that these masks, if successful, could be used by anyone to determine such properties as the minimum detectable defect size, the inspection speed, the number of missed defects, and the number of false indications for any particular inspection system or systems.

An MOS metallization pattern of moderate complexity was chosen as the basic pattern for this test mask. The smallest line widths or spaces in this pattern are $0.30 \mathrm{mil}(7.6 \mu \mathrm{m})$. The width of the basic pattern is $10.5 \mathrm{mils}$ $(0.27 \mathrm{~mm})$ and the height is $7.9 \mathrm{mils}(0.20$ $\mathrm{mm})$. Each die consists of a 10 by 10 array of the basic pattern which makes up the 120by $100-\mathrm{mils}$ (3.0- by $2.5-\mathrm{mm}$ ) die pattern. The final mask consists of a 14 by 14 array of dice on a 76- by 76-mm photomask with a die center-to-center spacing of $150 \mathrm{mils}$ $(3.81 \mathrm{~mm}$ ) in each direction. Of the 196 dice in the array, 15 contain intentional defects.

These 15 defective dice are inserted into the array by use of three $10 \mathrm{x}$ defect reticles of the same pattern, but with the intentional defects located at different random positions on each die pattern. Each of these defect reticles contains 36 intentional defects including pinholes, spots, breaks, bridges, intrusions, and protrusions; the distribution of these defects is given in table 8 . Each of the defect reticles is stepped into essentially randomly selected locations on the mask as shown in figure 7.

Clear-field test masks were fabricated by two independent, commercial mask suppliers using conventional state-of-the-art optical lithography. One supplier used a step-andrepeat system with a laser controlled stage; otherwise, the fabrication equipment employed was the same. Master masks were fabricated by stepping the defect-free reticle into 181 locations while skipping 15 locations. The three different defect reticles were stepped into these skipped locations. The test masks were made by contact printing the master masks into both chrome and iron oxide photomask blanks. Examination of these test masks through a microscope revealed that essential$1 y$ all of the defects $2.5 \mu \mathrm{m}$ and larger printed; nearly all of the smaller pinholes and about 10 percent of the smaller spots printed, giving a total of about 510 intentional defects per test mask and an average defect density of about $18 \mathrm{~cm}^{-2}$.

Run-out errors were measured on these test masks. These measurements were made along selected rows and columns of dice and made on scan lines located near the dice edges that were parallel to the scan direction. The 1ocations of these scan lines are indicated by the arrows in figure 7 . The run-out measurements were made from the centers of the first opaque line located on the leading edge of the die pattern with respect to the scan direction. These opaque lines were $7 \mu \mathrm{m}$ wide. The measurements were made on a commercially available linear comparator with a stated precision of $\pm 0.25 \mu \mathrm{m}$. Line centers were automatically located by the use of a photocell and signal balancing while a light beam dithered across the line. Thus, the line centers were respectively located at the centers of each symmetrical line image. Repeated measurements along each scan were within $0.25 \mu \mathrm{m}$ in all cases and in most cases were within $0.12 \mu \mathrm{m}$.

The run-out errors from two measurement scans, one across the top and the other across the bottom of row 12 of one of these masks, are plotted in figure 8 . These errors are typical of the run-out errors measured on all of the masks regardless of whether or not the masters were made on a laser controlled stepping stage and often exceed the required indexing accuracies listed in table 1 . Figure 8 shows that the die run-out errors exceed 1 $\mu \mathrm{m}$ at the location of defect reticle II. It is suspected that these large run-out errors are caused by errors in the positioning of reticle II in the stepping equipment and not by errors in the stepping stage. Figure 9 illustrates the respective die rotations implied by the run-out errors measured at the left and bottom edges of die patterns $(12,7)$ and $(12,11)$. For illustrative purposes the die patterns are represented as $1.5-\mu \mathrm{m}$ squares and show opposite rotations for the same die. Since a die cannot rotate in two opposite directions simultaneously, these phenomena are interpreted as caused by line distortions and edge waviness. Such distortions have a pernicious effect on the capability of automated inspection systems to detect real defects.

\subsection{Mask Inspection}

Photomasks made from the same runs as those masks on which the measurements were made, 


\section{COLUMN}

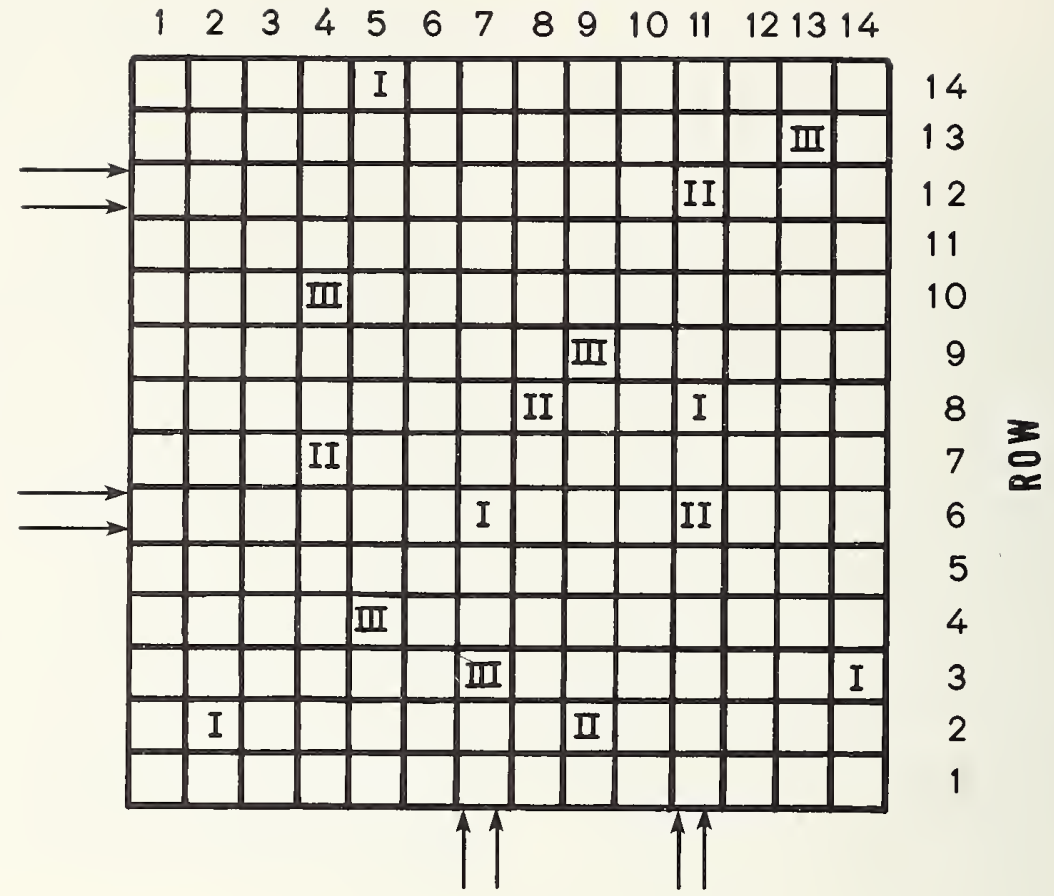

Figure 7. The 14 by 14 matrix of the defect mask showing the stepped locations of the three different defect reticles indicated by Roman numerals I, II, and III, respectively. (The arrows indicate the scan locations of the run-out measurements.)

Table 8 - Intentional Defects on the Defective Die.

\begin{tabular}{|c|c|c|}
\hline Type & Quantity & Print Size, $\mu \mathrm{m}$ \\
\hline Pinholesa & 14 & $7.6,6.4,5.1,3.8,2.8,2.5,1.9$ (two each) \\
\hline Spotsa & 14 & $7.6,6.4,5.1,3.8,2.8,2.5,1.9$ (two each) \\
\hline Breaks b & 2 & 7.6 wide \\
\hline Bridges ${ }^{b}$ & 2 & 7.6 wide \\
\hline Intrusions $b$ & 2 & $\begin{array}{l}\text { Halfway into a clear area } \\
7.6 \text { wide }\end{array}$ \\
\hline Protrusionsb & 2 & $\begin{array}{l}\text { Halfway into an opaque line } \\
7.6 \text { wide }\end{array}$ \\
\hline
\end{tabular}

Total per

reticle

36

$a_{\text {Round. }}$

$b_{\text {Made with straight edges. }}$ 


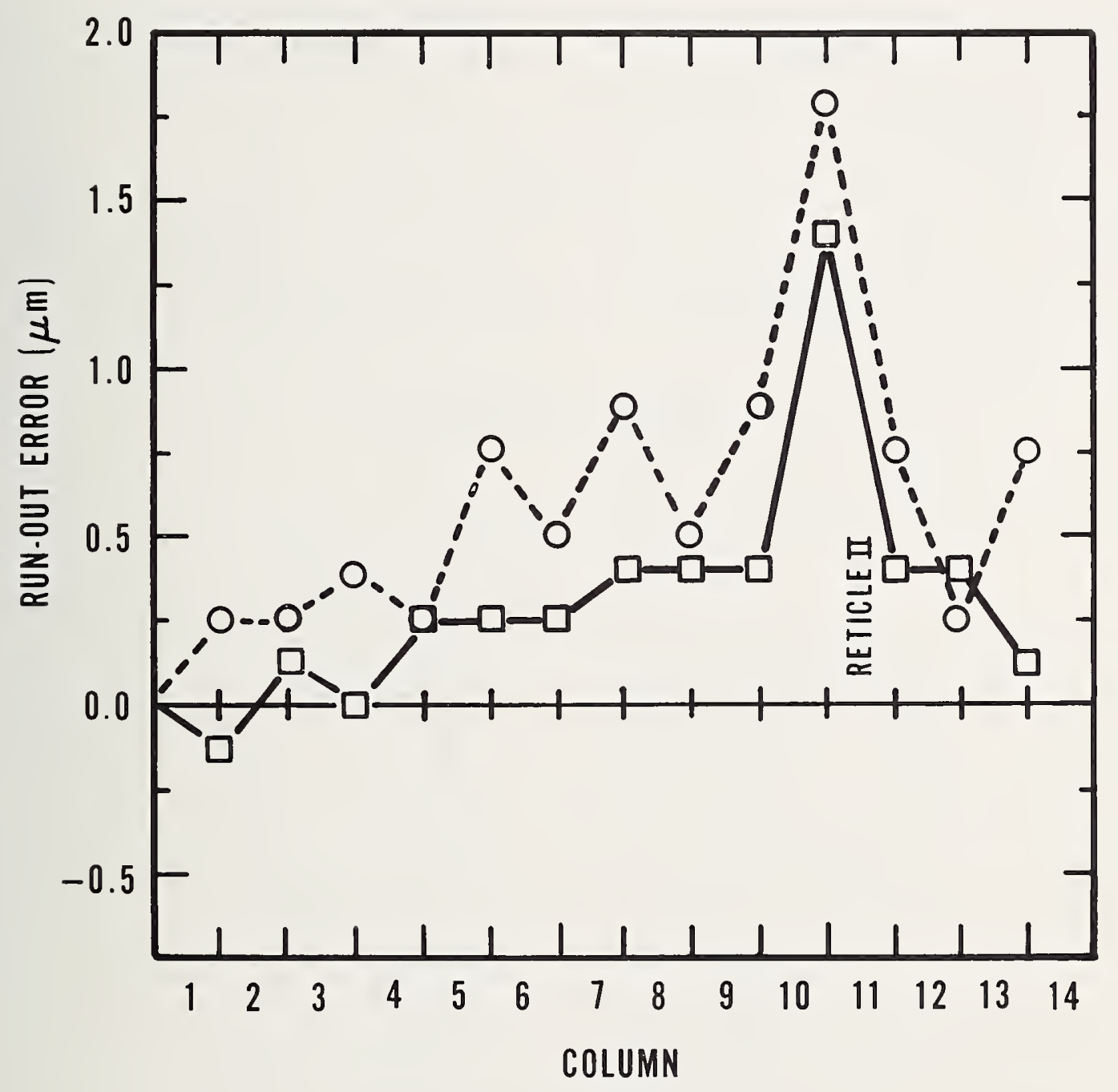

Figure 8. The run-out errors between the left edges on adjacent dice of row 12 of the defect mask as a function of column position ( $\square$ : values from the top scan; 0 : values from the bottom scan.) 


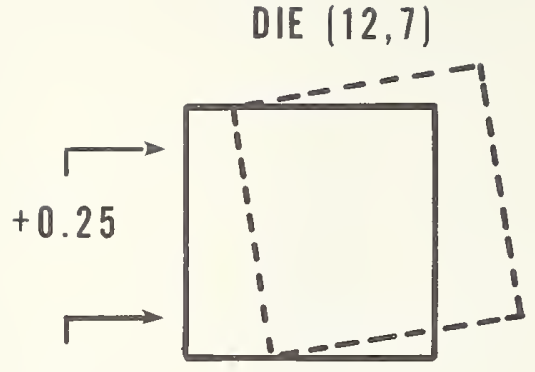

$+0.50$

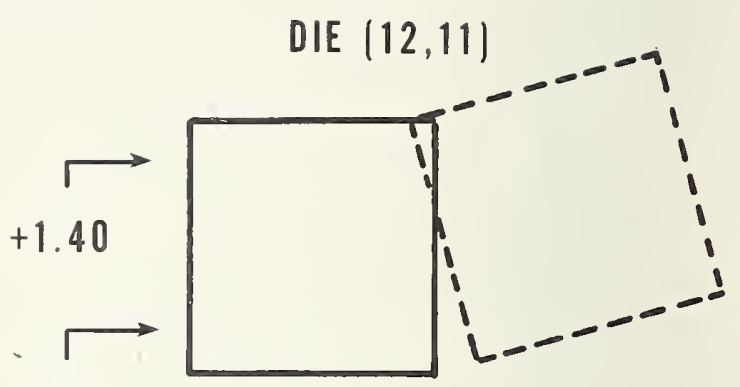

$+1.80$

\section{ROW MEASUREMENTS}
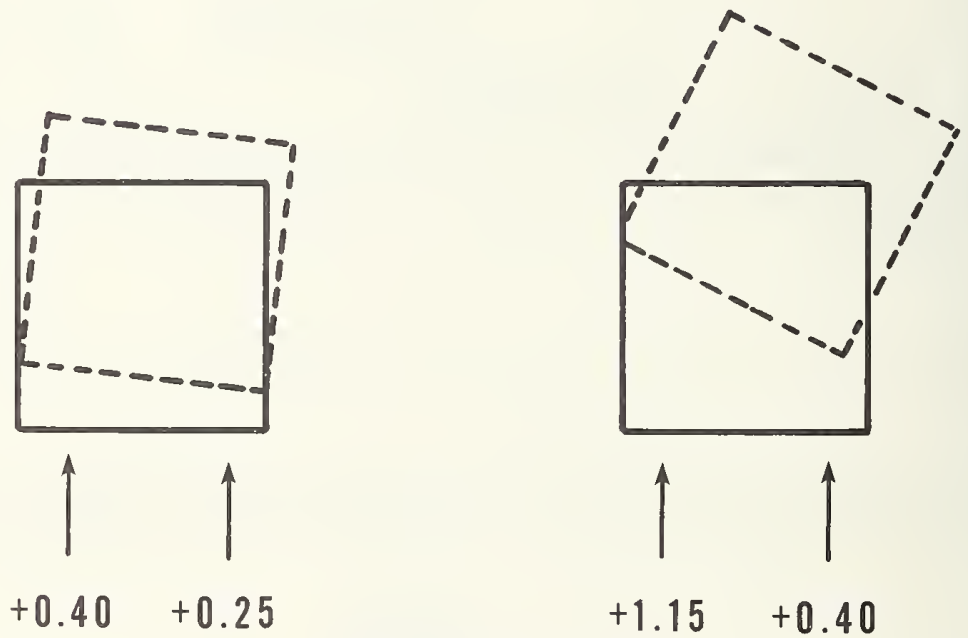

$+1.15+0.40$

\section{COLUMN MEASUREMENTS}

Figure 9. Illustration of the run-out errors from the scan measurements of the line centers. (Solid squares indicate the desired dice positions; dashed squares indicate the measured positions. The arrows indicate the positions of the runout scan measurements; the values associated with the arrows are the run-out errors in micrometers. For illustrative purposes the die patterns are represented as $1.5-\mu \mathrm{m}$ squares.) 
were sent to four independent installations possessing automated photomask inspection systems. These masks were packaged and shipped by mail. This presented a problem in that the masks were received with considerable amounts of particulate contamination which necessitated their cleaning before inspection. Since the cleaning thoroughness could not be assessed, all of the masks were guaranteed to have more defects than those intentionally fabricated into them.

The results of these inspections were as follows:

SYSTEM A - This system used the dualbeam, flying-spot scanning technique. During the inspection the spacing between the two flying spots had to be continually adjusted indicating that there were run-out errors on the mask. To alleviate some of these difficulties, the system threshold was set to detect minimum defects of $2.5 \mu \mathrm{m}$. Since this system was already set up to inspect an area somewhat smaller than that covered by the 14 by 14 mask array, only a 13 by 13 array of dice was inspected. The total number of defects was given as 540 and the corresponding defect density was about $24 \mathrm{~cm}^{-2}$. No information was supplied as to whether all of the intentional defects greater than $2.5 \mu \mathrm{m}$ were detected. The mask was fabricated with 420 intentional defects in the inspected area; thus, considerably more defects were detected by this inspection than were intentionally fabricated into the mask.

SYSTEM B - This system also used the dual-beam, flying-spot scanning technique. Considerable difficulty, primarily attributed to die orientation and run-out errors, was experienced. Contamination was also a problem. To avoid the detection of spurious defects caused by contamination and run-out errors, the system was adjusted to detect defects that were only $5 \mu \mathrm{m}$ and larger. Under these conditions only the intentionally defective die patterns were identified. No other information concerning the identity of defects or defective dice was provided.

SYSTEM C - This system used the spatialfiltering technique with incoherent illumination added to produce a background image of the entire mask for defect identification and location. None of the defects on the mask was found with this system.

SYSTEM D - This partially automated system consisted of an optical comparison technique that alternately displays, in rapid succession, two different superimposed die patterns. This system is similar in principle to the blink microscope used by astronomers to detect celestial objects [29] and required manual observation of the display to detect mask defects. Only the 15 intentionally defective dice were identified. No problems caused by run-out errors on the mask were reported. The inspection time was about 15 min.

Although the results reported from these tests were incomplete, it was clear that dimensional control of run-out, critical dimensions, and line edges is mandatory if masks are to be inspected by systems directly comparing one die pattern with another on the same mask. Specifically, the run-out error must be appreciably less than $0.5 \mu \mathrm{m}$ everywhere. This error includes the cumulative contributions from table yaws and drifts in the stepping equipment as well as lack of geometry uniformity due to chemical processing. While no experimental verification was established to assess the capability of other types of mask inspection systems to inspect masks with the type of dimensional errors described above, it appears from the analyses reported here that the above conclusion is valid for all types of automated mask inspection systems.

In principle, stepping errors can be overcome by the use of electronic alignment. This involves the continuous shifting of coordinate positions of the inspection data stored in an interfaced computer while the mask is being inspected. The increase in the inspection time that is added by this continuous alignment is expected to be unacceptable. An estimate of the increase in the inspection time may be made by considering the following: There are $1.44 \times 10^{9}$ separate areas of $2-$ by 2- $\mu \mathrm{m}$ size to be compared on the entire mask. If the computer memory consists of RAM memories with serial access or cycling times of $1 \mu s$ per bit and each stored word consists of 2 bits (required to store four levels of grayscale information which may consist of completely clear, completely opaque, and two intermediate gray levels), the total interrogation time for each word is $2 \mu \mathrm{s}$. Assuming that the electronic alignment requires a minimum of one data interrogation to determine the misalignment and a second interrogation to verify the realignment, the total time for the electronic alignment is equal to the sum of the cycle time per bit plus the access time per bit multiplied by the number of bits per word; for this example, an additional inspection time of 96 min results.

This increase in inspection time could be reduced by using memories with access and cycle times of $70 \mathrm{~ns}$ per bit which are predicted to 
become available in 1978 [30]. The use of these memories would reduce the additional time by a factor of $7 \times 10^{-2}$ to about $7 \mathrm{~min}$ which is an acceptable increase in the inspection time. However, in this model it is still assumed that only two data interrogations are necessary for complete alignment. Automated mask inspection devices reported to use such electronic alignment [5] use a minimum of one data shift, or two data interrogations, for the alignment in each of the $x$ and $y$-directions. Consideration of alignment in both of these directions increases the additional mask inspection times calculated above by a factor of 2 . The calculated additional times will also be increased if more than two data interrogations per direction are required. There is a possibility of reducing the additional inspection time by signal multiplexing, parallel data reading, and selective data interrogations, although selective data interrogations have the disadvantage of reducing the detection probabilities of misalignments caused by stage yaws and thereby increasing the probability of spurious defect detection. 
Four methods were analyzed for automated inspection for visual defects. The results of these analyses should be interpreted in a comparative sense to indicate which automated mask inspection methods appear most viable in light of the characteristics and properties considered. The properties and characteristics that were analyzed were primarily presented as areas that should be considered either by the prospective purchaser of an automated inspection system or a prospective manufacturer.

A general conclusion that can be made from this investigation is that an automated mask inspection system should be designed to do either visual defect inspection or dimensional inspection, not both. This is based on the fact that the principles involved in these two types of inspections are significantly different and accordingly require different designs for each application. The laser flying-spot scanning system can in principle be used for dimensional inspection in a microdensitometer mode; the data collected in this mode must be analyzed for lineedge locations, realizing that the illumination is coherent. The microdensitometer has utility in dimensional mask inspection, but its basic design limits its use for visual defect inspection.
An extremely important conclusion from this work is that, for visual defect inspections, the dimensional tolerances on the masks, both those of the feature dimensions in the die patterns as well as those in the dimensions between the die patterns, must be significantly smaller than the size of the minimum defect to be detected. This arises from the basic property of automated inspection systems to interpret the misalignment caused by the lack of such dimensional control as defects and the unacceptable time added if electronic alignment is used to compensate for this lack of control. Thus, before successful automated mask inspection systems can be made using the technologies as they are described here, much more dimensional accuracy must be achieved in mask making. This requires not only better measurement methods and control, but also better chemical processing to assure line and die pattern uniformity.

A conclusion that follows directly from the previous one is that these methods of mask inspection may be directly applicable to the inspection of printed circuits and possibly hybrid circuits. The sizes of the tolerable defects for these circuits are a much smaller fraction of the achievable dimensional control than it is for integrated circuit patterns.

\section{ACKNOWLEDGMENTS}

The authors would like to acknowledge the many individuals employed in the microelectronics industry and associated industries for their helpful discussions during the course of this work. We would like to express a special thanks and appreciation to the individuals who made the inspection measurements reported in section 4.2. We would also especially like to acknowledge Mr. Phil- lip Schultz of Lawrence Livermore Laboratory for continued assistance and advice during the analysis phase of this work. Appreciation and thanks are owed to Dr. D. Nyyssonen and $\mathrm{Mr} . \mathrm{R}$. Swing ${ }^{*}$ of the National Bureau of Standards for many helpful discussions on microdensitometers and related optics and to Dr. W. M. Bullis of NBS for his critical review of this manuscript.

* Now with General Electric Co., Space Division, Valley Forge, Pennsylvania. 
1. Schoonard, J. W., Gould, J. D., and Miller, L. A., Experimental Studies of Visual Inspection, IBM Research Report RC 3085, October 6, 1970.

2. Ciarlo, D. R., Schultz, P. A., and Novotny, D. B., Automated Inspection of IC Photomasks, Photofabrication Imagery 55, J. M. Graf and W. Converse, Eds., PP. 84-89 (Society of Photo-Optical Instrumentation Engineers, Bellingham, Washington, 1975).

3. Bruning, J. H., Feldman, M., Kinsel, T. S., Sittig, E. K., and Townsend, R. L., An Automated Mask Inspection System, IEEE Trans. EZectron Devices ED-22, 487495 (1975).

4. Dyer, D. L., Optical Limits in TV Microscopy, Research/Development 24, 4044 (1973).

5. Sandland, P., Automatic Inspection of Mask Defects, Developments in Semiconductor Microlithography II 100, J. W. Giffin and B. Ruff, Eds., PP. 26-35 (Society of Photo-Optical Instrumentation Engineers, Bellingham, Washington, 1977).

6. Hyzer, W. G., Image Analysis, Research/ DeveZopment 25, 44-49 (1974).

7. Kossyk, G. J. W., Laico, J. P., Rongud, L., and Stafford, J. W., The Primary Pattern Generator Part II - Mechanical Design, Belz Syst. Tech. J. 49, 2043-2059 (1970).

8. Chitayat, A. K., High Speed Positioning, Solid State Technology 16, 42-44 (1973).

9. Hartman, D. K., Glasbrenner, F. K., and Colangelo, D., Part I, Manufacturing in Process Control and Measuring Techniques of Mask Evaluation, AFML-TR-69-334 Technical Report, December 1970. (Available to qualified requestors from Defense Documentation Center, Cameron Station, Alexandria, VA 22314, Accession No. AD 881208.

10. Bourdelais, R. J., Colangelo, D., McFadyen, R. J., and Elliott, J. F., Instrument for Automatically Inspecting Integrated Circuit Masks for Pinholes and Spots, U.S. Patent 3,795,452, March 5, 1974. (Government-owned invention available for licensing; copy of patent available from Commissioner of Patents, Washington, DC 20231.)

11. Goodman, J. W., Introduction to Fourier Optics, pp. 83-90 and Chapter 7 (McGraw Hill Book Co., New York, N.Y., 1968).

12. Goodman, J. W., ibid., pp. 83-90.

13. Watkins, L. S., Inspection of Integrated Circuit Photomasks with Intensity Spatial Filters, Proc. IEEE 57, 1634-1639 (1969).

14. Heinz, R. A., Odenweller, R. L., Jr., Oehrle, R. C., and Watkins, L. S., Tool and Production Inspection by Optical Spatial Filtering of Periodic Images, The Western Electric Engineer 27, 39-56 (1973).

15. Watkins, L. S., Application of Spatial Filtering Subtraction to Thin Film and Integrated Circuit Mask Inspection, App Z. Opt. 12, 1880-1884 (1973).

16. Axelrod, N. N., Intensity Spatial Filtering Applied to Defect Detection in Integrated Circuit Photomasks, Proc. IEEE 60, 447-448 (1972).

17. Minami, M., Sekizawa, H., Masuda, H., and Watanabe, T., A New Mask Inspecting Device, Proceedings of the Micro-Electronic Seminar INTERFACE '76, Monterey, California, October 1976, pP . 67-80 (Eastman Kodak Company, Rochester, N.Y., 1977).

18. Jerke, J. M., Hartman, A. W., Nyyssonen, D. , Swing, R. E., Young, R. D., and Keery, W. J., Comparison of Linewidth Measurements on an SEM/Interferometer System and an Optical Linewidth-Measuring Microscope, DeveZopments in Semiconductor Microlithography II 100 , J. W. Giffin and B. Ruff, Eds., Pp. 37-45 (Society of Photo-Optical Instrumentation Engineers, Bellingham, Washington, 1977).

19. Nyyssonen, D., Linewidth Measurement with an Optical Microscope: The Effect of Operating Conditions on the Image Profile, Applied Optics 16, 2223-2230 (1977).

20. Nyyssonen, D., Optical Linewidth Measurements on Silicon and Iron-Oxide Photomasks, DeveZopments in Semiconduc- 
tor Microlithography II 100 , J. A. Giffin and B. Ruff, Eds., pp. 127-134 (Society of Photo-Optical Instrumentation

Engineers, Bellingham, Washington, 1977).

21. Swing, R. E., The Optics of Microdensitometry, Optical Engineering 12, 185198 (1973).

22. Swing, R. E., NBS, Private Communication: The criterion for underfilling and values derived from it are incorrect as they appear in reference [21]. They are stated correctly in this manuscript.

23. Swing, R. E., Conditions for Microdensitometer Linearity, J. Opt. Soc. Am. 62, 199-207 (1972).

24. Nyyssonen, D., Partial Coherence in Imaging Systems, Opt. Eng. 13, 362-367 (1974).

25. O'Callaghan, F. G., Clarke, H. C., Poindexter, R. W., Wray, J. D., and Benedict, G. F., Automatic Mask Inspection for Registration Errors and Critical Dimensions, presented at the Society of Photographic Scientists and Engineers Winter Symposium on Micro-Photo Fabrication, February 6-7, 1975, Palo Alto, California.
26. Welford, W. T., Length Measurements at the Optical Resolution Limit by Scanning Microscopy, Colloquia of the International Commission for Optics, Bruxelles, May 6-9, 1958, Optics in Metrology, P. Mollet, Ed., pp. 85-90 (Pergamon Press, New York, 1960).

27. Williams, C. S., and Becklund, O. A., Optics: A Short Course for Engineers and Scientists, p. 335 (John Wiley and Sons, Inc., New York, N.Y., 1972).

28. Ciarlo, D. R., IC Inspection Test Masks - Experimental Results, Lawrence Livermore Laboratory Report UCID 17391, February 14, 1977. (Available from National Technical Information Service, 5285 Port Royal Road, Springfield, VA 22161).

29. Anon., The Astronomer in the Engine Room, Time 106, pp. 75-76 (October 27, 1975).

30. Altman, L., One-Chip Controllers and 4-K Static RAMS Star, Electronics 50, p. 97 (1977).

31. Williams, C. S., and Becklund, O. A., op. cit., Chapter 5, pp. 98-129.

32. Goodman, J. W., op. cit., p. $166 \mathrm{ff}$. 
This appendix describes the details of the model used to calculate the profiles shown in figure 5. The scanning light spots for the dual-beam, flying-spot scanner described are produced by a laser beam and are coherent. Consequently, the intensity profile of an edge must be calculated for coherent light by first calculating the amplitudes of the light radiation, combining these amplitudes by superposition, and calculating the intensities by squaring these resultant amplitudes [31,32]. The model assumes that the phase is constant and that no phase changes occur across the edge. Thus, in a one-dimensional analysis the field amplitude of the light $\mathrm{P}(\mathrm{x})^{1 / 2}$ is found by convolving the amplitude distribution of the Gaussian light spot $g(x)^{1 / 2}$ with the amplitude attenuation of the line edge $T(x)^{1 / 2}$ where $P(x)$ is the transmitted light intensity, $\mathrm{T}(\mathrm{x})$ is the transmittance of the light absorbing material on the photomask, and $g(x)$ is the intensity distribution. Mathematically, this is written

$$
P(x)^{1 / 2}=\int_{-\infty}^{\infty} T(n)^{1 / 2} g(x-\eta)^{1 / 2} d \eta,
$$

where

$$
g(\zeta)^{1 / 2}=(h / \sqrt{2 \pi}) \exp -h^{2} \zeta^{2} / 2
$$

and

$$
\mathrm{T}(\zeta)^{1 / 2}= \begin{cases}1 & \zeta<0, \\ \exp -\mathrm{K} \zeta & 0<\zeta<\mathrm{q}_{e}, \text { and } \\ \mathrm{T}_{0} & \mathrm{q}_{\mathrm{e}}<\zeta .\end{cases}
$$

The transmittance function $T(\zeta)$ describes the transmittance of the physical edge profile shown by line $B$ in figure 5 . This material edge profile begins at $x=0$, rises at an angle $\phi$ above the horizontal, and extends to $\mathrm{x}=\mathrm{q}_{e} ;$ a film of constant thickness $\mathrm{t}_{0}$ and transmittance $\mathrm{T}_{\mathrm{o}}$ exists at values of $\mathrm{x}>\mathrm{q}_{e}$; no film exists at values of $\mathrm{x}<0$. The transmittance of the film is assumed to obey Lambert's law. The film edge shown in figure 5 has $\phi=55$ deg and a Lambert's law exponential constant $K=(2.303 \alpha$ tan $\phi) / 2$ where $\alpha$ is the absorbency determined by using the common base 10 instead of the natural base.

The scanning spot diameter $\mathrm{R}$ is obtained by assuming a diffraction limited lens with an impulse response given by ( $\sin a x) / a x$ with $a=\pi R$ for the one-dimensional case. This gives a value of $R$ equal to one-half of the characteristic width of this impulse response function which is the distance between the first node points on each side of the line ax $=0$.

To facilitate the mathematics, a Gaussian function, ( $h / \sqrt{\pi}) \exp -h^{2} x^{2}$, which is normalized such that its integral over all values of $x$ is equal to 1 , was fit to the intensity of the one-dimensional impulse response. The constraints imposed were that the x-coordinates of the half-maximum points of the Gaussian function and ( $\sin \mathrm{ax} / \mathrm{ax})^{2}$ be equal which gives a value $a x=1.38$ at the half-intensity point. Using this value, the relation between $R$ and $h$,

$$
R=\frac{\pi \sqrt{1 \mathrm{n} 2}}{1.38 \mathrm{~h}}
$$

was obtained. Equation (A-1) can be solved explicitly for the intensity $P(x)$ in terms of the tabulated error function

$$
\operatorname{erf}(x)=\frac{2}{\sqrt{\pi}} \int_{0}^{x} e^{-s^{2}} d s
$$


and is

$$
\begin{gathered}
\mathrm{P}(\mathrm{x})^{1 / 2}=(1 / 2)[1-\operatorname{erf}(\mathrm{hx} / \sqrt{2})]+ \\
(1 / 2) \exp \left\{\mathrm{K}^{2} /\left(2 \mathrm{~h}^{2}\right)-\mathrm{Kx}\right\}\left[2-\operatorname{erf}\left(\frac{\mathrm{K}-\mathrm{h}^{2} \mathrm{x}}{\sqrt{2} \mathrm{~h}}\right)-\operatorname{erf}\left(\frac{\mathrm{K}-\mathrm{h}^{2} \mathrm{x}}{\sqrt{2} \mathrm{~h}}+\frac{\mathrm{hq} e}{\sqrt{2}}\right)\right]+ \\
\left(\mathrm{T}_{\mathrm{o}} / 2\right)\left[1-\operatorname{erf}\left(\mathrm{h}\left(\mathrm{q}_{\mathrm{e}}-\mathrm{h}\right) / \sqrt{2}\right)\right] .
\end{gathered}
$$

Values of $P(x)$ calculated from this equation were used to plot the profiles shown in figure 5 . 



\section{PERIODICALS}

JOURNAL OF RESEARCH-The Journal of Research of the National Bureau of Standards reports NBS research and development in those disciplines of the physical and engineering sciences in which the Bureau is active. These include physics, chemistry, engineering, mathematics, and computer sciences. Papers cover a broad range of subjects, with major emphasis on measurement methodology, and the basic technology underlying standardization. Also included from time to time are survey articles on topics closely related to the Bureau's technical and scientific programs. As a special service to subscribers each issue contains complete citations to all recent NBS publications in NBS and nonNBS media. Issued six times a year. Annual subscription: domestic $\$ 17.00$; foreign $\$ 21.25$. Single copy, $\$ 3.00$ domestic; $\$ 3.75$ foreign.

Note: The Journal was formerly published in two sections: Section A "Physics and Chemistry" and Section B "Mathematical Sciences."

DIMENSIONS/NBS (formerly Technical News Bulletin)This monthly magazine is published to inform scientists, engineers, businessmen, industry, teachers, students, and consumers of the latest advances in science and technology, with primary emphasis on the work at NBS. The magazine highlights and reviews such issues as energy research, fire protection, building technology, metric conversion, pollution abatement, health and safety, and consumer product performance. In addition, it reports the results of Bureau programs in measurement standards and techniques, properties of matter and materials, engineering standards and services, instrumentation, and automatic data processing.

Annual subscription: Domestic, \$12.50; Foreign \$15.65.

\section{NONPERIODICALS}

Monographs-Major contributions to the technical literature on various subjects related to the Bureau's scientific and technical activities.

Handbooks-Recommended codes of engineering and industrial practice (including safety codes) developed in cooperation with interested industries, professional organizations, and regulatory bodies.

Special Publications--Include proceedings of conferences sponsored by NBS, NBS annual reports, and other special publications appropriate to this grouping such as wall charts, pocket cards, and bibliographies.

Applied Mathematics Series-Mathematical tables, manuals, and studies of special interest to physicists, engineers, chemists, biologists, mathematicians, computer programmers, and others engaged in scientific and technical work.

National Standard Reference Data Series--Provides quantitative data on the physical and chemical properties of materials, compiled from the world's literature and critically evaluated. Developed under a world-wide program coordinated by NBS. Program under authority of National Standard Data Act (Public Law 90-396).
NOTE: At present the principal publication outlet for these data is the Journal of Physical and Chemical Reference Data (JPC'RD) published quarterly for NBS by the American Chemical Society (ACS) and the American Institute of Physics (AIP). Subscriptions, reprints, and supplements available from ACS, 1155 Sixteenth St. N.W., Wash., D.C. 20056.

Building Science Series-Disseminates technical information developed at the Bureau on building materials, components, systems, and whole structures. The series presents research results, test methods, and performance criteria related to the structural and environmental functions and the durability and safety characteristics of building elements and systems. Technical Notes-Studies or reports which are complete in themselves but restrictive in their treatment of a subject. Analogous to monographs but not so comprehensive in scope or definitive in treatment of the subject area. Often serve as a vehicle for final reports of work performed at NBS under the sponsorship of other government agencies.

Voluntary Product Standards-Developed under procedures published by the Department of Commerce in Part 10, Title 15, of the Code of Federal Regulations. The purpose of the standards is to establish nationally recognized requirements for products, and to provide all concerned interests with a basis for common understanding of the characteristics of the products. NBS administers this program as a supplement to the activities of the private sector standardizing organizations.

Consumer Information Series-Practical information, based on NBS research and experience, covering areas of interest to the consumer. Easily understandable language and illustrations provide useful background knowledge for shopping in today's technological marketplace.

Order above NBS publications from: Superintendent of Documents, Government Printing Office, Washington, D.C. 20402.

Order following NBS publications-NBSIR's and FIPS from the National Technical Information Services, Springfield, Va. 22161 .

Federal Information Processing Standards Publications (FIPS PUB)-Publications in this series collectively constitute the Federal Information Processing Standards Register. Register serves as the official source of information in the Federal Government regarding standards issued by NBS pursuant to the Federal Property and Administrative Services Act of 1949 as amended, Public Law 89-306 (79 Stat. 1127), and as implemented by Executive Order 11717 (38 FR 12315, dated May 11, 1973) and Part 6 of Title 15 CFR (Code of Federal Regulations).

NBS Interagency Reports (NBSIR)-A special series of interim or final reports on work performed by NBS for outside sponsors (both government and non-government). In general, initial distribution is handled by the sponsor; public distribution is by the National Technical Information Services (Springfield, Va. 22161) in paper copy or microfiche form.

\section{BIBLIOGRAPHIC SUBSCRIPTION SERVICES}

The following current-awareness and literature-survey bibliographies are issued periodically by the Bureau:

Cryogenic Data Center Current Awareness Service. A literature survey issued biweekly. Annual subscription: Domestic, $\$ 25.00$; Foreign, $\$ 30.00$.

Liquified Natural Gas. A literature survey issued quarterly. Annual subscription: $\$ 20.00$.
Superconducting Devices and Materials. A literature survey issued quarterly. Annual subscription: $\$ 30.00$. Send subscription orders and remittances for the preceding bibliographic services to National Bureau of Standards, Cryogenic Data Center (275.02) Boulder, Colorado 80302. 
National Bureau of Standards

Washington, 0.C. 20234

POSTAGE ANO FEES PAIO U.S. DEPAATMENT DF COMMERCE $C O M-215$

OFFICIAL BUSINESS

SPECIAL FOURTH-CLASS RATE BOOK 